
(C) Kent State University 2014. All rights reserved. Duplication of the material contained herein is strictly prohibited without the express written consent of the Editor of The Journal of SPORT.

ISBN-13: 978-1505422054

ISBN-10: 1505422051

ISSN: 2328-7624 


\section{Contents}

The Logistical Management of the Organizational Stress of Elite

"Pipeline" Athletes: Interventions of National Performance

Directions in an Olympic Year

Faure and Appleby....

Title IX Proportionality Prong: Compliance of Division 1 FBS

Universities

Simon, Dieringer, Wanless, Tyner, Judge....

Cross Cultural Differences in Consumer Evaluation of Cobranding in Sport

Lee, Pierce, Kim, Krill \& Felver

You Have the Right to Tweet, But It Will Be Used Against You:

Balancing, Monitoring and Privacy for Student-Athletes McCoy........................................................221

About the Journal of Sport....................................246 

The Journal of SPORT, 2014, 3(2), 139-183

(C) Kent State University

\title{
THE LOGISTICAL MANAGEMENT OF THE ORGANIZATIONAL STRESS OF ELITE "PIPELINE" ATHLETES: INTERVENTIONS OF NATIONAL PERFORMANCE DIRECTORS IN AN OLYMPIC YEAR
}

\author{
Caroline Faure \\ Idaho State University \\ Karen M. Appleby \\ Idaho State University
}

\begin{abstract}
Numerous research studies have examined the relationship between organizational stress and organizational effectiveness, especially in relation to athlete performance. The purpose of this case study was to investigate the process by which National Performance Directors (NPDs) of a single U.S. Olympic sport program attempted to prevent and manage the organizational stress of their athletes in preparation for and participation in international competition in an Olympic year. Results indicated the NPDs were aware of the causes of stress identified in the literature. Despite a lack of formalized sport psychology training, the NPDs assumed responsibility for managing these stressors, relying on past personal experience as elite athletes to guide them. Critical to prevention and management of stress were facilitating environments conducive to maximizing athlete performance, creating ample support structures, communicating among constituent groups, and managing relationships through the development of social cohesion.
\end{abstract}




\section{Introduction}

Organizational performance is one of the most important constructs in sports management. Fletcher and Hanton (2003) stressed, "sport organizations and personnel working with elite performers need to be aware of and sensitive to the complex social and organizational environment they are constantly shaping" ( $p$. 193). One key element that is relevant to performance in sport is stress. Stress, and how organizations manage and control stress for athletes, can have considerable effects on the athletes' behavior both in training and competition. In 1982, Shirom defined the term organizational stress as "work-related social psychological stress" (p. 21). It was not until more than a decade later that researchers began to study organizational stress in sport environments. Mirroring Shirom's definition of organizational stress, Woodman and Hardy (2001) clarified that organizational stress encompasses only the stress that stems directly from an athlete's relationship with the sport organization. When not managed appropriately, organizational stress can have a detrimental impact on performance (Woodman \& Hardy, 2001).

Ioana et al. (2012) warned that stress could lead to an athlete's inability to concentrate and actively participate in the activity at hand. Adapting to the specific conditions of the competitive environment can also be affected by the presence of stress. Therefore, sport organizations that are serious about supporting athletes at the elite level should pay careful attention to the environment within which their athletes are operating and how their organizational processes minimize negative stress for competitors (Fletcher \& Hanton, 2003). This is especially important when it comes to supporting high performance program, or pipeline athletes, a subset of elite athletes who some National Governing Bodies (NGB's) feel have the most realistic chance of making an Olympic team.

Often, the effectiveness of a sport organization is defined by its ability to manage organizational stress. Organizational effectiveness refers to an organization's ability to successfully manage its internal and external affairs and achieve positive outcomes (Richard, Devinney, Yip \& Johnson, 2009). In the sport 
setting, organizational effectiveness can pertain to the management of team travel, marketing and fundraising efforts, public relations requests, and maximizing athlete performance through coaching, nutrition, injury management, and psychological interventions. Organizational effectiveness can also include aspects of support pertaining to athlete performance such as “...organizational culture, resources and support, communication and atmosphere, long-term planning, internal procedures, activity level, efficiency of throughput process, realization of aims, interest in athletes, and caliber of board and external liaisons" (Hanton, 2011, p. S180). It is believed that effective organizations may have a competitive advantage because athlete distractions are minimized. Research has suggested that organizational stressors can negatively impact athletes' performance specifically when organizations do not provide opportunities to enhance feelings of perceived control (Hanton, Wagstaff, \& Fletcher, 2007).

Minimizing stress in elite athletes, especially those select few who are considered as pipeline athletes, has become a focal point for National Performance Directors (NPDs) in sport. Fletcher and Arnold (2011) found that NPDs invest a considerable amount of time in identifying and articulating a vision and argued that it is important for elite sport leaders to not only establish and express a team's ultimate aspiration, but also to disseminate its vision, role model its message, and inspire individuals to invest in it. Similarly, Gould and Maynard's (2009) literature review of research on Olympic athletes suggests that organizational effectiveness and support can have a large influence on the performance of athletes. The findings of this study suggest that successful Olympic athletes generally reported their sport organizations positively impacted their performance through the following: (a) providing appropriate support personnel (i.e., coaching staffs and sport psychologists), (b) facilitating a supportive team atmosphere, (c) helping athletes create realistic performance objectives, and (d) minimizing distractions from sources within the host city.

While there have been several studies that have investigated the sources of organizational stress on elite athletes at international competition (Fletcher \& Hanton, 2003; Woodman \& Hardy, 2001), 
Fletcher and Wagstaff (2009) warned that there is not sufficient research regarding performance management in elite sport. They recommended researchers explore how sport leaders and managers create, optimize, and maintain a high performance environment. Therefore, the purpose of this case study was to investigate the process by which NPDs of a single U.S. Olympic sport program attempted to prevent and manage the organizational stress of their high performance, or pipeline, athletes in preparation for and participation in international competition during an Olympic year. While there have been several studies that have investigated the source of stress on elite pipeline-level athletes, especially at the Olympic Games (Woodman \& Hardy, 2001; Fletcher \& Hanton, 2003), this study is significant because it is the first to examine the way that NPDs perceived stress and attempted to prevent and manage it within a single Olympic sport program. The exploration of this topic will be valuable for NPDs and other sport managers who deal with competition logistics. While limited to one sport, we feel the results of this study can assist other sport leaders as they attempt to minimize athlete stressors and maximize performances.

\section{Methods}

This qualitative study followed an interpretive case study approach. Case studies are defined as an "intensive, holistic" approach to research that provides and "in-depth understanding of a single unit or bounded system" (Baumgartner \& Hensley, 2006, p. 210). According to Yin (2003), a case study approach is an appropriate framework to use when investigating an individual organization. Further, case studies analyze people, events, decisions, periods, projects, policies, institutions, and/or other systems that are studied holistically by one or more methods while contextually analyzing a limited number of events or conditions and their relationships (Marshall \& Rossman, 2006; Thomas, 2011).

Researchers have used the case study research method for many years across a variety of disciplines. Social scientists, in particular, have made wide use of qualitative research methodology to examine contemporary real-life situations and provide the basis for the application of ideas (Yin, 2003). Interpretive paradigms suggest that 
the social world is subjective and complex and that "...people define their own realities" (Silk, Andrews, \& Mason, 2005, p. 7).

Therefore the interpretive case study approach that we utilized in this study allowed us to investigate the participants' subjective meaning in relation to their experiences of organizational effectiveness and stress.

\section{Participants, Instrumentation and Procedures}

We recruited and obtained interviews from two National Performance Directors (NPDs) and a Senior-Level Administrator (SLA) from a single NGB of sport affiliated with and supported by the United States Olympic Committee (USOC). NPD1 had worked with the NGB for six years previous, while NPD2 was in his first year, although he had also served in a similar capacity with another country's NGB for ten years prior to being recruited to come assist the United States' team. Additionally, both NPDs had prior histories of competing in the sport at an elite level. The SLA who participated in this study had been with the organization for 14 years prior to the start of this study, overseeing the sport's administration at both the grassroots and elite levels.

To gain an understanding of the methods used to prevent and manage organizational stress of their pipeline athletes, we used an in-depth, semi-structured interview approach along with participant observation. Prior to data collection, an interview guide was constructed based off of previous research related to the impact of organizational stress on athletes. Areas of specific concern related to (a) organizational issues, (b) environmental issues, (c) personal issues, (d) leadership issues, and (e) team issues (Fletcher \& Hanton, 2003; Woodman \& Hardy, 2001). The semi-structured interview protocol allowed us to explore specific areas of interest pertaining to the purpose of the study while also allowing for a flexible conversational style interview to occur (Patton, 1990). Interviews were conducted in person at the start of the 2012 international competition season (May) and again at the conclusion of the season (October). In addition to the personal interviews, we were able to observe the NPDs and athletes at three separate international events spread across the 2012 competition season (including the Olympic 
Games in London) in order to shed light on information obtained from the onsite, semi-structured interviews. While we were restricted access to the athletes at the events and were only able to observe the interactions of the athletes and NPDs from a distance, we were able to conduct multiple personal onsite interviews with the NPDs at each of the venues, with the exception of the Olympic Games. We were able to interact onsite with the NPDs for no fewer than two days but not more than five days leading up to each event, most often at the team's hotel or at practice venues, and through the day after each event. These interviews lasted anywhere from ten minutes to two hours in length. We recorded and transcribed all interviews and returned those transcripts to the interview participants via electronic mail for verification. The observation techniques used in this study were helpful in triangulating the data acquired from the interviews. According to Patton (1990), observational data permits us to understand a program or treatment to a greater extent when compared to only conducting interviews. Simply stated, detailed researcher observation provided us with the opportunity to identify and make sense of the "complex interactions" that describe a social situation (Marshall \& Rossman, 2006, p. 99). As part of the observation, we also recorded field notes during each of our observations. These field notes included both descriptive and reflective content. While the field notes helped us recall some of the specific details surrounding each race day, their usefulness was limited as this study purported to merely examine the way that NPDs perceived stress and their attempt to prevent and manage it. Therefore, the interview transcripts proved to be much more valuable than the field notes in this retrospective study. We were also provided with full access to the NPDs electronic communications with athletes throughout the year. This included all documentation of team and athlete itineraries for the year, coaching and training logs, and travel details. The NPDs also granted us an open line of communication throughout the year, both by phone and e-mail correspondence. To provide additional perspective, the SLA gave us access to the NGB's financial reports and organizational bylaws for review. 


\section{Data Analysis}

After the participants verified the interview transcripts electronically, a process of a priori coding commenced. This analysis process was deemed appropriate as the purpose of this study was not to build theory but, rather, to investigate and describe the elements of organizational effectiveness and stress that had been predefined in the literature that occurred in this specific case. This is a preliminary step in the theory building process. As Eisenhardt (1989) suggests, "A priori specification of constructs...is valuable because it permits researchers to measure constructs more accurately" (p. 536). The previously identified categories cited by Fletcher and Hanton (2003) and Woodman and Hardy (2001) provided the themes for organizing the interview transcripts. Thus, there were five themes: Organizational Issues (subthemes of sport development and support), Environmental Issues (subthemes of team selection, finances, training environment, travel, and competition environment), Personal Issues (subthemes of nutrition, injury, and goals and expectations), Leadership Issues (subthemes of coaching and coaching styles), and Team Issues (subthemes of team atmosphere, support networks, and communication). The subthemes presented were also consistent with the a priori themes identified by Fletcher and Hanton (2003) and Woodman and Hardy (2001). Then, we each jotted comments beside the raw content to note salient phrases that related to the a priori categories previously identified. Afterwards, we collaboratively reviewed their independent transcript notes and compared the data across thematic categories. We conducted parallel coding and then solicited the critique of a senior qualitative researcher uninvolved with other aspects of this study to verify the constructs as a quality control measure. No inter-rater reliability statistics were computed, as the goal of this analysis was not to test the investigators' ability to identify common themes, but to establish a common understanding of the meaning of the various themes through extensive exploration and discussion of the participants' views and actions. Biddle et al. (2001) suggested that readers should be provided with an opportunity to evaluate and interpret interview data in a way that is most meaningful to them. Therefore, the findings of this study are 
presented using both hierarchical content trees and direct quotations. Review of the provided organizational documents and bylaws helped us understand those processes more holistically. Specifically, the bylaws helped provide background information and helped us understand the overarching principles the guided the organization. Other documents, including budgets, financial reports, travel logs, and elite athlete newsletters helped us understand the grand scale of day-to-day operations, including general expenditures, athlete endorsements, travel itineraries, nutritional logs, coaching methods, and Olympic team selection.

\section{Results}

As stated, previous research indicated there were five main categories of organizational stress that affected elite athletes: organizational issues, environmental issues, personal issues, leadership issues, and team issues (Woodman \& Hardy, 2001; Fletcher \& Hanton, 2003). As stated, these overarching themes and subsequent subthemes were specifically targeted during the interview and observation process (Table 1). 
Table 1. Thematic Constructs Examples of Raw Data Themes and Subsequent Subthemes and Major Themes

\begin{tabular}{|c|c|c|}
\hline Raw Data & Sub Theme & Theme \\
\hline $\begin{array}{l}\text { The sport was added to the Olympics in } \\
2000 \text { and it was a game changer. }\end{array}$ & $\begin{array}{l}\text { Sport } \\
\text { Development }\end{array}$ & $\begin{array}{l}\text { Organizational } \\
\text { Issues }\end{array}$ \\
\hline \multicolumn{3}{|l|}{$\begin{array}{l}\text { There isn't a strong culture for the sport } \\
\text { in the United States. }\end{array}$} \\
\hline \multicolumn{3}{|l|}{$\begin{array}{l}\text { There has been a focus on youth and } \\
\text { junior oriented programming to help } \\
\text { create talent for the future. }\end{array}$} \\
\hline \multicolumn{3}{|l|}{$\begin{array}{l}\text { We start } 2016 \text { preparation at the same } \\
\text { time we are sending our } 2012 \text { athletes to } \\
\text { the Olympics. }\end{array}$} \\
\hline It helps that our numbers are small. & Support & \\
\hline \multicolumn{3}{|l|}{$\begin{array}{l}\text { In theory you could have a staff of } 10, \text { but } \\
\text { it's just not practical }\end{array}$} \\
\hline $\begin{array}{l}\text { Criteria announced several years in } \\
\text { advance. }\end{array}$ & Team Selection & $\begin{array}{l}\text { Environmental } \\
\text { Issues }\end{array}$ \\
\hline \multicolumn{3}{|l|}{$\begin{array}{l}\text { We have right of performance and history } \\
\text { of performance. }\end{array}$} \\
\hline $\begin{array}{l}\text { Through the Athletes' Advisory Council, } \\
\text { the athletes participate in decision- } \\
\text { making. }\end{array}$ & Finances & \\
\hline \multicolumn{3}{|l|}{$\begin{array}{l}\text { Athlete who is more of a medal } \\
\text { contender may get more - not always a } \\
\text { democracy. }\end{array}$} \\
\hline \multicolumn{3}{|l|}{$\begin{array}{l}\text { It's about pre-empting as well as } \\
\text { [knowing] who are the individuals on the } \\
\text { team and what are their personal traits }\end{array}$} \\
\hline We arranged the travel. & Travel & \\
\hline \multicolumn{3}{|l|}{ Discourage stay at Olympic Village. } \\
\hline \multicolumn{3}{|l|}{$\begin{array}{l}\text { Just entering the village becomes like } \\
\text { getting into Fort Knox... }\end{array}$} \\
\hline $\begin{array}{l}\text { We try to make things familiar to the } \\
\text { athlete. }\end{array}$ & $\begin{array}{l}\text { Competition } \\
\text { Environment }\end{array}$ & \\
\hline \multicolumn{3}{|l|}{$\begin{array}{l}\text { We can only control the things we have } \\
\text { control over. }\end{array}$} \\
\hline \multicolumn{3}{|l|}{$\begin{array}{l}\text { We reinforce psychological strategies } \\
\text { (such as visualization). }\end{array}$} \\
\hline $\begin{array}{l}\text { We actually had somebody... who served } \\
\text { in our role as being the key nutritionist for } \\
\text { our team. }\end{array}$ & Nutrition & $\begin{array}{l}\text { Personal } \\
\text { Issues }\end{array}$ \\
\hline USOC support & Injury & \\
\hline $\begin{array}{l}\text { We vet and hire local professionals, if } \\
\text { needed. }\end{array}$ & & \\
\hline
\end{tabular}




\begin{tabular}{|l|l|l|}
\hline $\begin{array}{l}\text { To consistently produce podium finishes } \\
\text { in international competition. }\end{array}$ & \\
\hline Most athletes have their own coaches. & $\begin{array}{l}\text { Goals \& } \\
\text { Expectations }\end{array}$ & \\
\hline We become their surrogate coach. & Coaching & $\begin{array}{l}\text { Leadership } \\
\text { Issues }\end{array}$ \\
\hline $\begin{array}{l}\text { It's just about communicating with } \\
\text { athletes' coaches. }\end{array}$ & & \\
\hline $\begin{array}{l}\text { It's about knowing the athletes and } \\
\text { knowing what makes them tick. }\end{array}$ & Coaching Styles & \\
\hline $\begin{array}{l}\text { We [try to] deliver a world-class practice } \\
\text { and educate the athlete so they don't } \\
\text { have a dependency on the program if } \\
\text { we're not there. }\end{array}$ & & \\
\hline $\begin{array}{l}\text { We know the relationship history with } \\
\text { each athlete. }\end{array}$ & & \\
\hline $\begin{array}{l}\text { Create a culture around the team...of } \\
\text { mutual respect. }\end{array}$ & $\begin{array}{l}\text { Team } \\
\text { Atmosphere }\end{array}$ & Team Issues \\
\hline $\begin{array}{l}\text { I really like the concept of social cohesion } \\
\text { as opposed to team cohesion. }\end{array}$ & & \\
\hline We have many roles to play. & & \\
\hline $\begin{array}{l}\text { It's not practical to have a large support } \\
\text { structure of personnel. }\end{array}$ & $\begin{array}{l}\text { Support } \\
\text { Networks }\end{array}$ & \\
\hline We communicate with coach & Communication & \\
\hline $\begin{array}{l}\text { Internal communications (Athletes } \\
\text { Advisory Committee, team meetings, } \\
\text { electronic) }\end{array}$ & & \\
\hline
\end{tabular}

\section{Organizational Issues}

According to Woodman and Hardy (2001), organizational stress is a construct that describes the "interaction between the individual and the sport organization within which that individual is operating" (p. 208). Therefore, the major theme of Organizational Issues discusses systemic organizational matters that may cause stress for an athlete and impact performance. Within the category of organizational issues, two subthemes were explored. These were (a) sport development, and (b) support.

Sport development. The SLA noted he considered his sport relatively young and said that it had only been included in three Olympic Games (prior to London). NPD1 acknowledged considerable growth of the sport since Olympics inclusion, calling it 
a "game changer." The SLA cited the NGB's grassroots membership at just over 155,000. Ongoing relationships with the United States Olympic Committee (USOC), including a residency program at the U.S. Olympic Training Center in Colorado Springs, also benefitted the organization and its athletes. Established NGB bylaws guide the organization's governance. NPD1 felt the sport's culture in other parts of the world was stronger than in the United States and attributed the lack of development groups to the historical lack of pipeline athlete performance results. The NGB has worked on developing its "High Performance" program in recent years. This program provides coaching and financial support to youth and collegiate aged athletes who meet established performance standards. NPD1 clarified that "we start 2016 preparation at the same time we are sending our 2012 athletes to the Olympics."

Support. In addition to administrative, membership, marketing and communications, events, and sport development staff, the organization supported two performance directors to oversee logistical management of the NGB's National Team. Their duties included some coaching. Both NPD1 and NPD2 acknowledged the small number of athletes they work with "helps." NPD2 summarized the duties of his position related to the Olympic Games:

It's an overseeing role. It's a decision-making role at times, and it's a role to make sure that the athletes and their coaches, who have worked very hard over four years, walk away...knowing that they did everything that they could and the results will be what they be. Having viewed all the races this year and having viewed all the races for the last ten years, I try to put that knowledge into place and make sure that the athletes are ready to go and stick to their plans, that they're best equipped heading into the race, and, specifically on race day, they're prepared to handle whatever unfolds during the race.

The NPDs managed other types of funding-related stress in a number of ways. One way was through the provision of support services. One of the NPDs had previously served in a similar capacity in 
another country. His experience, he said, helped him identify a wide variety of support services that many pipeline athletes in the sport would like to use for performance. However, he said due to finance issues, such services might not be a realistic use of organizational funding. The NGB had more than 400 athletes it recognized as being elite, or worthy of competing against other professionally tiered athletes at some international level. However, not all 400 of those elite athletes were considered by the NGB to be capable of performing well at the highest level of international competition. Approximately 40 of those athletes classified as elite competed internationally in top-tiered events, and 17 were considered by the NGB as pipeline athletes, or those the NGB targeted as having the most realistic shot at making their Olympic team, based on their sport's international qualification criteria. Due to the relatively small size of the sport, the NGB only staffed two performance directors to oversee these Olympic prospects. The NPDs were aware that a perceived lack of support personnel could cause stress for certain athletes:

In theory you could have a staff of 10, but it's just not practical.... Although the athletes would like their [own] individual [support personnel], they're pretty quick to point out that [at the NGB] there's maybe more staff than athletes. [They question if] the money is being well spent.

Thus, additional personnel resources (such as sport physiologists and psychologists) were allocated to the NGB by the USOC, as requested and indicated.

\section{Environmental Issues}

Within the category of environmental issues, the following subthemes were identified in the literature review to be sources of athlete stress and were therefore addressed: (a) team selection, (b) athlete funding, (c) travel, (d) training environment, and (e) competition environment (Woodman \& Hardy, 2001).

Team selection. Since Olympics inclusion in 2000, the NGB had only produced one Olympic medal and had failed to produce 
pipeline athletes that consistently ranked among the world's elite. Improvement in this area was clearly identified as a primary focus by both the SLA and the NPDs. The SLA also stated that his organization clearly outlined criteria for athletes to qualify for its National Team, and that criteria was guided by an "Athletes' Advisory Council" (AAC), as mandated by the organization's bylaws. Three athlete directors (which include the two NPDs) and four elite athletes serve as members of the AAC. The purpose of this council was to "broaden communication between [the NGB] and all its athletes" (not just the subset of elite athletes the NGB considers to be pipeline athletes) and to "make recommendations to the Board of Directors on issues related to the needs and concerns of elite athlete members." When discussing National Team program selection, the SLA referred us to the stated goals and objectives of the program:

The goal of the [name of NGB] National Team program is to have consistent podium performances on the international stage at the highest competitive level. It is a three-tiered system which provides administrative, performance, and financial support to assist athletes in achieving optimal results for themselves and the Team at the Olympic Games, Pan Am Games, and [name of world championship events]. The National Team is composed of those athletes with proven performance capability at the most competitive international level and is not intended to serve as a development pathway.

Secondarily, as part of its High Performance Program, which caters mostly to the organization's pipeline athletes, the NGB supported an initiative intended to "bridge the gap between Junior Elite athletes, Collegiate Elite athletes and the National Team Program [current and future pipeline athletes] in the [name of NGB's] pipeline." The SLA reported this program aimed to "prepare athletes for the advancement through each level of [international competition] events... and entry to the National Team Program." Athletes were selected to these programs based on history of athletic performance and established performance standards. 
A more specific area of athlete stress that was discussed and subsequently managed by the NPDs and SLA was that of Olympic Team selection. Again, the AAC assisted the NGB in outlining the procedure for team selection. The sport's International Federation (IF) determined the number of Olympic slots each country would have based on world championship rankings and NGB participation at international events, with a maximum allocation of three slots per gender, per country. It was determined by the IF that the United States would be allocated three starting positions for women and two for men.

To address this potential source of athlete stress, the NGB clearly outlined the qualification criteria for the 2012 Olympic Team 18-months prior to the first selection event, a timeline required by the USOC. This process was, in part, further restricted by criteria set forth from the sport's International Federation. In early 2010, the process of team selection was communicated to pipeline athletes in three ways: (a) through the NGB's website, (b) through the NGB's printed national magazine publication, and (c) through a separate publication sent to all elite athletes affiliated with the NGB. The top two performing American athletes in each gender at a predetermined international event in 2011 were given "automatic" berths on the 2012 Olympic Team, providing they placed in the top nine overall at that event. At another event in early 2012, eligible athletes placing in the top nine at this event would automatically claim the remaining slots. Should fewer American athletes place in the top nine overall than Olympic Team slots available, the NGB would award those slots on a discretionary basis. Going into the 2012 event, the NPDs discussed how the organization had a good idea, based on past performances, which athletes would make the team:

While there are 17 [USA] athletes here...generally speaking the athletes who are most apt to qualify for our team are athletes who we already have down. So, it's very rare in our sport that somebody comes out of nowhere to qualify for the Games. 
This performance expectation was a significant factor in managing organizational stress for athletes because these athletes had been working with the NPDs for a long period of time, and therefore the relationships between the two groups were considered strong. As NPD1 stated, "Really for the last two, if not even four years or longer we've been following [those athletes] with a degree of attentiveness to understanding how they work, how they operate, and what they need."

Athlete funding. Another area frequently related to athlete stress was athlete funding. The NPDs acknowledged considerable expenses were incurred by both the NGBs and by athletes looking to compete at the highest levels. In 2012, the NPDs personally supported approximately 40 High Performance and National Team members at eight international events spread across four continents, and also five athletes at the Olympic Games. The SLA reported total expenses of the NGB to be just under $\$ 11.8$ million for 2011 with approximately $\$ 2.2$ million directed specifically to its High Performance program. Since the sport was included in the Olympic Games in 2000, the NGB has seen enormous growth in both grassroots and elite membership as well as total revenue. The total dollars spent on the High Performance program has increased substantially over these same years, however, the High Performance allocation in relation to overall NGB expenses has decreased. The SLA also stated that the Athletes Advisory Council participates in decisions regarding funding of specific High Performance athletes, and the AAC has additional athlete representation on the NGB's Budget Committee.

NPD1 reported that "anywhere between a quarter and a third" of his sport's funding came from the USOC. The rest of the financial resources were acquired primarily through the sport's grassroots membership (which consisted of more than 155,000 in 2012) and events (more than 3,500 in 2012), through marketing efforts, and through corporate sponsorship agreements. During the 2012 Olympic year, the NGB had access to five on-campus resident spots in Colorado Springs and also had the ability to fund two offcampus residence spots. Externally funded scholarships provided an additional eight off-campus residences. While off-campus residents 
were required to pay their own housing expenses, they were able to have access to train and eat at the Olympic Training Center.

Through the USOC, NPD1 said there was additional funding available for those High Performance athletes considered as "medal contenders." Such athletes were provided with health insurance plus a "living stipend" or "cash contribution" to help offset the costs with full-time, year-round training. "It's kind of like when an athlete qualifies for a scholarship at a university and they live off-campus versus on-[campus]," NPD1 said. "They get a set amount that's supposed to cover living expenses. And so the athlete can use it for rent, or for a car payment, or for gas, or for whatever. It's to help them not have to worry about having a job on top of it." Other elite athletes outside that top tier of pipeline athletes received health insurance with a more limited stipend and are forced to solicit private sponsorships to pay the enormous expenses that result from international training and travel. NPD1 explained how his NGB's partnership with the USOC dictates some facets of athlete funding:

They basically give us one spot per Olympic spot that we could obtain [top level funding]. The third major contribution from the USOC would be proving a residence athlete spot where they have the ability to access and use the Olympic Training Center from a facilities standpoint, room and board, etc. Those are the three key things an athlete might receive from the USOC. The USOC also gives us some funding to run our program. So that's where our decision-making comes in.

The athletes represented on the National Team had a considerable amount of input related to their own individual funding to supplement living expenses. Prior to the competition season, each athlete's individual coach presented the NGB with a competition and performance plan the clearly identified what races and training camps they planned to attend and at what cost. The NGB reviewed each proposal to ensure alignment to the organization's goals and expectations and allocated additional funding, as indicated. NPD1 noted that his organization considered the potential for "performance 
and return on investment" as the deciding factors for additional funding requests.

The NPDs frequently discussed a concept called "right of performance" that guided how the organization made decisions about funding certain athletes:

The grant money we get from the USOC coupled with our revenue streams or budget we allocate for our athletes [is distributed] as we see fit for travel to races or [to fund] supporting specialists that might focus on nutrition or biomechanics or dialing in [equipment]. Those would be the areas where we take a look at performance plan for an athlete for a season and identify and determine what are the key, critical races [and] what are the things that [the athletes] really need from a development standpoint or an improvement standpoint or a maintenance standpoint.

Both NPD1 and NPD2 acknowledged an additional fiscal challenge associated with funding other developmental elite athlete programs within their NGB. The SLA reported assistance to this program involved management staffing along with the development of talent through mentorship and coaching relationships. They contended that such developmental programs, which ranged from junior elite programs through post-collegiate elite programs, were vital in order to ensure the NGB's long-term international success in the sport.

Travel. As noted earlier, the NGB paid for its elite pipeline athletes to travel to top-tiered international competition. This consisted of all travel expenses consistent with the competition and performance plans submitted to the NGB prior to the season, and assistance with travel logistics (airline and hotel). Because the athlete's trained and resided in cities that spanned the globe, the athletes had the ability to choose their own travel itinerary, but that itinerary had to be approved by the NGB. This approval process gave the NPDs an opportunity to ensure all travel-related stress (such as a lengthy airport layover) was avoided. In most cases, all athletes stayed at the same designated hotel. 
Prior to arriving in London, each athlete was provided with a "Performance Guide," which outlined a number of specific areas of interest. Included in the guide was all information relative to logistics. This included (a) lodging accommodations and contact information, (b) local weather, (c) local currency, (d) airline arrivals and departures of the entire team and support staff, and (e) ground transportation schedules for each athlete for the duration of the trip. Contact information for each athlete and the NGB's support staff (NPDs, chiropractor, massage therapist, and personal coaches) was also included. Each staffer's roles and responsibilities were clearly described. General information relative to athlete processing, participation in Opening Ceremonies, allocation of team apparel was also provided along with how the athletes could access the Internet and obtain guest passes to the Olympic Village. Drug testing policies were described in detail. Information surrounding the team's prerace "training camp" outside of London was provided, complete with photos of all indoor and outdoor training facilities. Training schedules for each day were meticulously documented, as were London-based schedules leading up to the events. Race information highlighted specifics related to the sport venue, and a list of other competitors (hyperlinked to full athlete profiles) was provided. Finally, an itinerary highlighted the full activities of the team (including meals, training activities, Games-related activities, and media commitments) for each day while in England.

While these guidelines were clearly in place for the athletes, things did not always happen according to plan. In one case, the NPDs were faced with an issue related to the late arrival of one of their athletes to London for the Olympic Games. At the advice of her coach, the athlete elected not to travel to London until three days prior to her event. She forewent the team's training camp outside of London, choosing instead to do all pre-race preparations in the same European town she resided and trained in year-round. Her flight into London arrived the night before the athletes' pre-race briefing, and the NGB support staffer who picked her up forgot to bring the athlete's credential. In order to attend that briefing and have the opportunity to practice at the sport venue the next morning, she needed to have her athlete credential validated. There were only two 
sites in London where athletes could have their credentials validated at night. These were at the airport and at the Olympic Village. This meant after the athlete arrived from the airport at the team hotel, she had to be immediately taken to the Olympic Village to have her credential validated. By the time this occurred, it was late at night and she had to navigate through large crowds. NPD1 summarized, "It was a long day of travel for her and then a late night running around. It certainly wasn't the best situation for her to deal with two days before the biggest race of her life."

Housing for the Olympics presented unique challenges, as well. While staying at the Olympic Village was an option, the NPDs contended staying there posed enormous logistical issues for training that would inevitably lead to considerable stress and potentially impact performance. Therefore, NPD1 described why the decision was made at the administrative level to not have the athletes stay in the Olympic Village:

Just entering the village becomes like getting into Fort Knox from the standpoint of getting through the metal detectors and having credentials checked and re-checked and triple checked. One of the simple reasons we're not staying in the village for the duration of our competition is the fact that it's kind of hard to leave and come back to the village a number of times throughout the day. If you are going to go out [to train] it's not in a quiet ...friendly environment.... There [might be] some [training] you could do...relatively nearby, but [it would be difficult] for them...to get to the security exit [and] then leave and then get through throngs of people.

Training environment. Another notable source of environmental stress that the NPDs attempted to prevent and manage was that of the training environment. To prepare for the climate and conditions of international settings, the NGB sponsored and promoted "training camps" and "preparation camps" in regions where athletes could train with other international athletes on courses that resembled those they had seen or would see in international competition. These camps occurred throughout the 
calendar year, including in the weeks leading up to the Olympic Games.

When managing training activities while at international competition sites, NPD1 noted, "Most of the time achieving performance is anything but easy," and even though he was only responsible for a total of five athletes at the Olympic Games, he acknowledged it "was about having five different people having five different things going on," and that it would be "easier to have them all doing the [same] thing but that was not always realistic.

The NPDs were well aware of the various stresses associated with competition environments and how they can potentially impact athlete stress and performance. The NPDs suggested that the staff needed to know each athlete on an individual level in order to manage this stress from an organizational standpoint:

What we work on doing is identifying and evaluating what are the greatest needs to athletes and we provide support mechanisms to cover those. We know there's not a mold that's going to work for everyone.... I think one of the big things from the vantage point of the athlete that freaks them out is the unknown. It's coming in and being out of their comfort zone because of things that don't know. We really work hard to eliminate some of the unknowns. We come down here and we give them as much information as we can that we think is relevant to [each of] them... we feed that information out so there's a familiarity before they get here.... It's about pre-empting as well as [knowing] who are the individuals on the team and what are their personal traits [and] what are the kinds of questions we are going to get from them. We know who gets anxious and who doesn't get anxious and we know why certain individuals get anxious. So we target certain areas so that we can keep certain people happy in certain areas. Then it'll be easy [for those athletes].... If we know our athletes correctly then we can pretty easily come up with solutions to things that come up against that we maybe didn't see coming. 
Within the National Team, the performance directors recognized that many of their Olympic prospects had their own competitive coaches. While it was essential to plan team workouts, adapting to the needs of these coaches was also of paramount concern to ensure minimal stress affected each athlete:

If they want to get a general...workout in a day, they may be very comfortable just going out and doing it on their own. They may grab a teammate casually. They may have a personal coach here with them.... So, we make sure they have access to the things they're going to need. And then for the things we think can be more loosely structured, we put the onus of responsibility on them and let them know if they need more structure we can help provide more structure.... With 17 people being coached by, I think, 16 different coaches, there's a little bit of everything thrown in there. So, you kind of provide the basic template so that everyone can paint [his or her] own picture.

Training in foreign countries presented unique challenges. While preparing for the Beijing Olympics in 2008, NPDs said the Olympic chaos along with air pollution proved to be a significant factor that affected the team's ability to train. Because of that, the team traveled to South Korea to finalize race preparations. For the 2012 Games, the NPDs arranged for both the men's and women's teams to stay approximately 40 kilometers southwest of the city of London from the day after the Opening Ceremonies until two days prior to the event. This gave the athletes the opportunity to focus on their training in a more less populated, quiet area. NPD1 had traveled to the area one year prior to the Games to secure the arrangements, which included a hotel, indoor and outdoor training facilities, catering, and a private transport company that would provide athlete, equipment and other personnel transport into and out of the city of London and sport venue. Two days prior to each event, the team moved to and headquartered at a hotel near the sport venue. 
Competition environment. When it came to the actual competition, NPD1 again acknowledged that communication with the athletes' coaches was critical:

There [are] some common things that are fundamental, whether it's cues, how do they motivate their athlete, what are the tools the athlete might use or what do they do, what do they use on a daily way that they might need to be reminded on. It might be, 'Have you done your visualization, because your coach tells me that every day you visualize before you [work out]?' So, it's just promoting that stuff and in some cases you get the opportunity to enhance the performance.

Still, NPD2 acknowledged that many things related to race performance are outside of the NPDs control:

You have to hand it over at a certain stage and say, 'We have done everything we can. We have facilitated your needs.' At some point you need to hand it over and say, 'It's up to you now!' That's one of the benchmarks I'll use.... Before the race starts we go over the checklist and ask if we did all the things beforehand that we know contribute to performance. If I can say 'yes', then actually my job is done. If the athletes win, fantastic! If they don't, it's probably something that was on their side of the fence as far as getting ready.

The Olympic environment was reported to be more stressful for athletes. The role of the NPDs was to structure that environment so that it resembled a typical race setting:

It's about continuing routine and keeping it pretty simple and keeping them on track. [You remind the athletes], 'This is what you do', you know, and [help them in] identifying what their needs are. In coming to the Games, it's about creating an environment that addressed all their needs and empowering them. 
NPD2 added, "We are sometimes held hostage. We can have the world's best organization but you can only look as good as your athletes perform."

\section{Personal Issues}

Within the category of personal issues, three subthemes were shown by previous researchers to cause athlete stress. These were (a) nutrition, (b) injury, and (c) goals and expectations (Woodman \& Hardy, 2001).

Nutrition. The NPDs each acknowledged that nutrition was a personal choice for their athletes. However, the vast amount of international travel done by the 17 pipeline athletes posed a unique challenge when it came to maintaining consistent diets. As stated, a caterer was contracted for the London Games and provided meals planned by USOC nutritionists three times daily. NPD1 said they concentrated additional attention on making support staff available to the athletes in an effort to help them make appropriate nutritional choices when traveling internationally, including to the Olympic Games:

[In] Beijing, the nutrition aspect was so much different than London. We actually had somebody who happened to be an advisor to an athlete who also used to work for the USOC who served in our role as being the key nutritionist for our team. Because of both the concern about food sourcing and the concern about heat and humidity, he played the role of being the urine analysis person [and tested] hydration at several points during the day for each athlete and [he also] focused on nutrition.

Injury. The NPDs discussed that part of managing this stress is also related to making sure that appropriate medical and physiological support staff are on hand in foreign locations. For the Olympics in London, only five credentials were provided to the NGB. This limited the number of support personnel that could accompany the team. NPD1 said the allocation of those five credentials were to a "team leader, head coach, chiropractor, 
massage therapist, and then our fifth one was actually more for the public vs. for us. It was the media person who kind of led the telling of the story." During non-Olympic international events, such staffers typically did not travel with the team. In those cases, if additional medical support networks were deemed necessary, the NGB chose to find appropriately qualified personnel in the remote setting. NPD2 added, "If I know that someone needs, say, a chiro[practor] once...we get off the plane and, we can [out]source a chiro[practor] locally who speaks English and we've vetted that they're qualified, they're insured, we know they're very capable... setting up those networks [is important]."

Goals and expectations. Another source of stress for athletes that the NPDs discussed for athletes was managing personal goals and expectations. Individual athletes and their coaches consistently managed goals and expectations on a monthly, weekly, and daily basis. However, it became clear that, while in the competition environment, the NPDs also helped athletes manage those goals and expectations. The NPDs said key to accomplishing this was "knowing the individuals [and] knowing what makes them tick." From a managerial standpoint, however, the NPDs noted the individual goals of athletes also had to be balanced with the goals of the organization:

Within [the] group you might have an athlete who, due to right of performance, is more of a medal contender than someone else.... On race day there will be one person to stand on the top of the podium and ideally...you would like that [to be] your athlete.... Whatever you have invested you [need] to get a return on that investment. So, you do focus on...whatever it takes to maximize the potential and minimize the risk of not getting that performance on race day.

\section{Leadership}

Within the category of leadership, the subthemes of (a) coaching and (b) coaching styles were explored. Each was 
previously identified as a potential source of stress for elite athletes (Woodman \& Hardy, 2001).

Coaching. As stated previously, many of the elite pipeline athletes within the NGB elected to have their own individual coach. Allowing for this and working collaboratively with each coach was viewed as important by the NPDs. One strategy they used was getting to know the coaches personally:

Coaches can be the hardest.... It's knowing the coaches, knowing how they work and how they like to operate, [and] knowing how they operate [with]in their home environment. We pick [the athletes] up when a lot of the work has been done. So, all our job is to, it's not even enhancing, it's actually just trying to replicate what it is that they do well at home so again when they come in it's not foreign.

At events where the athlete's individual coach could not be present, the NPDs assumed the coaching duties. NPD1 referred to this as becoming "surrogate coaches":

We become the person who facilitates what the coach would normally do...you know if they were there. And there are a variety of reasons why coaches actually wouldn't go or the athlete wouldn't want them to go and I think it's one of the things in this organization is creating the opportunities where, especially for the Olympics, and my interest in the Olympics is if you can just replicate what you've done many times before then you probably will have good performance.

NPD2 reiterated the importance of knowing each athlete and his/her unique personality and needs. He stated, "It's just about that concept of making sure there's minimal anxiety here that's in our control. If we know our athletes correctly then we can pretty easily come up with solutions to things that come up against [them] that we maybe didn't see coming." NPD2 added that having insight to the strategies utilized by each athlete's coach also helps: 
It's just about communicating with the coach, and there [are] some common things that are fundamental, whether it's cues, how do they motivate their athlete, what are the tools the athlete might use or what do they do, what do they use on a daily way that they might need to be reminded on. It might be, 'Have you done your visualization?' So, it's just promoting that stuff and in some cases you get the opportunity to enhance the performance.

Coaching styles. The NPDs discussed that the athletes and coaches, sometimes, have very unique relationships in that they may not live in the same city. Therefore, some of the coaching occurred via distance (i.e., training plans sent electronically along with telephone communications). At the past two Olympic Games, The NGB's NPDs invited the athletes' personal coaches to come to the event hoping this would have a positive impact on the athlete. However, NPD1 found this sometimes had the opposite effect on some athletes:

There are some athletes who I think benefit from that and some athletes who probably don't benefit from having the coach there. Some of it is time in the sport; some of it is the daily interaction.... We have some coaches who don't live in the same city as their athletes, so the athletes don't deal with them 365 days out of the year. So, all of a sudden they've gone from seeing their coach maybe one day a month or one day every three months, maybe talking regularly, but not...you know, what happens when you throw them in the environment where they're on top of each other 10, 12, 15, 20 days in a row getting ready for the biggest competition of their lives.

NPD2 added the stress of the Olympics added to the challenge faced by the NPDs. He stated,

Not many people step-up in [our sport] but a lot of people step down.... If you want to find someone who wins, you 
actually have [to find] someone who doesn't bring anything more on [Olympic] race day than what they've done [at other competitions]. There are many athletes who, for whatever reason, under the pressure of the Games, which is a really unique environment, [fail to perform well].... There are variables that you've just got to have a plan for - every single one. You always hope that you don't ever have to deal with that, but you've got an answer for every scenario. Rehearsal is the key and that's why it's good to have the coaches [at the Olympics].

One aspect of coaching style discussed by the NPDs was the need they felt to help their athletes become more independent and to develop skills to manage their own stress and issues that happen in competition settings. As NPD2 said, "At some point you need to hand it over and say, 'It's up to you now!" This level of leadership transcends into mentoring and helping to create athletes who are mentally prepared for the stressful events that they will encounter when racing on an international circuit. The NPDs discussed the concept of wanting the athletes to be able to function and perform well in high stress situations even when their coach or the NPDs were not there to support them. NPD2 clarified, "I'm not big on dependency, so you want to have that environment so that if something happens and their coach isn't there that the athlete isn't dependent on the coach."

While the concept of managing athlete stress was described as a complex and dynamic issue, it was singly focused on athlete success. Each of the NPDs discussed how this leadership leads to athlete success by helping to eliminate or control the pressures of the competitive environment. The ways in which NPDs work with athletes to manage the unique types of stress associated with the magnitude of the Olympic Games aligned nicely to the concept of creating an independent athlete. NPD2 mentioned, "People get... a bit star-struck by it and they tend [to] veer away from what they [normally] do. And so you start saying, 'Why are you doing that because you never do that?" There can also be added stressors that arise once the athlete leaves the NPD and enters "the clean zone" 
where only those with athlete credentials can go. According to NPD2, it is an ongoing challenge in sport psychology:

So, you know, how do [we get] the athletes [to] get on the start line [and be] immune to the pressures and the uniqueness of the Olympics in a negative sense [while experiencing]...double the positives.... so that [to them] it just feels like it's another event where they can just [compete] to the best of their ability.

\section{Team Issues}

The final major theme to emerge from the interviews was the concept of managing team issues. Within this theme, three subthemes were explored. These consisted of (a) team atmosphere, (b) support networks, and (c) communication (Woodman \& Hardy, 2001).

Team atmosphere. While their sport is contested individually, there were team elements that posed unique challenges for the NPDs. These contradictory factors had the potential to create issues with social and team cohesion, especially when athletes were competing for highly coveted spots on the Olympic Team.

NPD2 discussed how this team component was managed by helping the athletes develop a sense of social empathy. He stated, "It's just about creating respect and empathy across your peers what would you do and what would you like to have done in that situation? It's a real mutual thing across your peers." Further, both NPDs suggested that creating an effective social environment for the athletes is also based on a level of trust that the athlete knows the organization has the best interest of the athlete at heart. NPD2 said, "You create a culture around the team that everyone knows that we've got their best interests at heart and we're going to do the best we can at getting them to the races and putting them on the start line ready for the best performance they can.... The reality is that it's about the athletes."

However, this empathic approach was not always realistic and, therefore, managing team dynamics and the stress involved sometimes became quite complex. Again, the NPDs mentioned that 
knowing the athletes on an individual level and carefully monitoring the social environment helps them avoid creating undue stress for athletes:

There may be two athletes who whether you know it or don't, and hopefully you do, that those athletes wouldn't be the best roommates for one another. [You have to make] sure you understand the situation. Some things are unpredictable or unknown. You roll a van up, or two vans up, and the two people that probably hate each other the most, and [you] end up with one bench left and they end up having to sit next to each other. I mean, some things you can control like roommate situations and some you can't, like that. Just being aware and being alert and be able to look around and see and evaluate the environment to understand and know the issues and be as pre-emptive as possible to eliminate those factors that could cause problems [is important].

During major competition such as the Olympic Games, the NPDs mentioned that the social cohesion can serve as a unique and positive source for performance if all of these factors are managed well:

It's driven by this common denominator, and that's the beauty of going to the [Olympic] Games and [it is] also the pressure of going to the Games. It actually unites the group around the realities of what it [means] to go to an Olympic Games. For most groups, actually...it is a bond that's hard to explain that actually enhances things.

Support networks. As stated earlier, funding dictated the provision of support networks, in particular in areas of medical and physiological support. The NPDs contended that considerable cost could arise from the provision of additional support personnel for the athlete. While most athletes require minimal outside support, NPD1 said he had some athletes who needed a more robust mechanism of support. This included access to biomechanists, personal chefs and sport psychologists. Some athletes he has worked with in the past 
needed as many as 15 people in their support network, while others find two or three sufficient. Again, understanding each athlete's needs was critical to the NPDs ability to optimally support them, as was ample communication with each athlete's private coach.

Accommodating the needs and desires of the athletes' families also became a focal point for the NPDs. While accessibility to the athletes and to the races seemed easy to obtain during two of the international competitions, this was not the case at the Olympic Games. In London, we recognized the limitations of the NPDs in this area. With five athletes competing and tickets scarce, athletes' families were forced to view the competitions from public areas. Often, this meant competing with more than a million spectators for optimal vantage points of the race.

Communication. As repeated throughout this paper, communication between the NGB, the NPDs and the athletes and athletes' coaches was critical. Methods of communication varied. Representation on the Athletes' Advisory Council and monthly meetings of the AAC ensured ongoing, two-way communication between the National Team members and the NGB's administration.

Communication between the NGB, its NPDs, the athletes, and the athletes' coaches was on going throughout the year. The geographic diversity of the athletes posed a challenge. NPD1 explained there were four primary methods of communication. First, a monthly newsletter was sent electronically to all elite athletes. This newsletter highlighted program updates, issues related to rules and or IF sport governance, event information, and changes in NGB protocols and/or staffing. Second, mass marketing materials were distributed quarterly and mailed to all the NGB's members. These publications highlighted programs, event results, organizational issues, and provided athlete features. The materials were posted on the organization's website, as well. Third, the NPDs met with each National Team athlete and his/her coach on a monthly basis. Each athlete and his/her coach was required to provide monthly status updates. NPD1 referred to this as "guaranteed monthly contact." Fourth, additional communication was administered either in person or by phone and sent electronically to elite athletes. In many cases, this communication was related to event specific topics. 


\section{Discussion}

The purpose of this case study was to investigate the process by which NPDs of a single U.S. Olympic sport program attempted to prevent and manage the organizational stress of their high performance athletes in preparation for and participation in international competition in an Olympic year. Previous research has identified main inhibitors of athlete success were lack of funding, facilities, sports science and medical support, specialist high-level coaching, team structure and organization, training and competition, and lifestyle (Duffy, Lyons, Moran, Warrington \& McManus, 2006; Fletcher \& Hanton; 2003; Woodman \& Hardy, 2001). All of these areas were confirmed as sources of stress targeted by the NPDs in our study.

In order to fully contextualize the results of this study, it is important to understand the growth of the sport that was studied and how that growth has impacted the NGB's philosophy on preparing athletes. As noted, the sport was added to the Olympic program in 2000 , and since that time, the organization had evolved from an unstructured, almost laissez faire approach to a highly structured, business-like approach. In that time, the organization has also evolved its ability to be effective in the areas of team travel, marketing and fundraising efforts, public relations requests, and maximizing athlete performance through coaching, nutrition, injury management, and psychological interventions. As such, we should also be reminded of Gould and Maynard's (2009) review of literature on Olympic athletes that suggested (a) providing appropriate support personnel (i.e., sport psychologists and coaching staff), (b) facilitating a supportive team atmosphere, (c) helping athletes create realistic performance objectives, and (d) minimizing distractions from sources within the host city can help to reduce athlete stress and maximize performance outcomes.

Researchers have suggested that organizational structure provides an essential function in optimizing athlete success. It has even been suggested that ineffective sport organizations compromise athletic performance (Lee, Christopher, Fletcher \& Hanton, 2007). In their study of performance leadership and management in elite sport, Fletcher and Arnold (2011) discovered that one of the main roles of 
a NPD was the management operations within the team, involving financial management, strategic competition and training planning, athlete selection for competition and upholding rules and regulations. Thus, NPDs have a critical role in not only managing their High Performance Program development but also in optimizing resources and processes. The results of this study supported this notion. Both NPDs employed with the NGB noted previous experience as an elite athlete. This is congruent with the findings of previous researchers who found that, "coach credibility (e.g. elite status and knowledge), reciprocal trust and respect, understanding the athlete's needs and responding accordingly, and caring about an athlete as a person and not just a performer" were critical factors in building coach-athlete relationships (Gould \& Maynard, 2009, p. 1398). The NPDs discussed a high level of concern with clarifying athlete selection for the both the National Team and the Olympic Games, being consistent and fair with athlete compensation, and providing a critical support role when it came to managing and creating a comfortable and well-organized competitive environment that could foster a foundation for athlete success.

Multiple internal and external stakeholders or constituent groups can make competing or conflicting demands, which can in turn pose a threat to an organization's ability to be effective. The NPDs in this study acknowledged that they were "spread thinly" at times, and that the athletes who consistently performed at higher levels often were the subjects of the most attention. The NGB featured in this study was challenged with the enormous task of managing more than 400 elite athletes in various elite athlete subgroups within the NGB, along with managing the sport's grassroots operations, which consisted of more than 155,000 members and 3,500 separate domestic events. The SLA of the NGB studied presented a clear hierarchical structure in which elite athlete operations were separate from grassroots operations. Additionally, within its elite athlete structure, focus groups concentrated on the facilitation of athlete development at a variety of age levels, thereby ensuring the continuation of the pipeline for future success. Being able to focus on such a "small" group was cited as being helpful to the NPDs. As indicated by previous research, when organizations are 
forced to manage and satisfy the demands of various subgroups, suboptimal performance may result.

\section{Maximizing Athlete Performance}

Gould, Flett, and Bean (2009) purported that cognitive, emotional, and behavioral strategies athletes and teams use is related to optimal psychological states and peak performance. The results of this study suggest that the NPDs of this NGB attempted to help increase the organizational effectiveness, as defined as athlete performance, by helping to manage the factors related to organizational stress for athletes in international competition, including at the Olympic Games. Some of these factors were within the NPDs control, while others were not.

The results of this study certainly suggested that the NGB's NPDs were attempting to create a culture of performance among their athletes while recognizing the sources of organizational stress. These stressors have been well documented in the literature as having a negative impact on athlete, specifically in international athletic settings (Kristiansen \& Roberts, 2010). Fletcher and Arnold (2011) predicted that, the "best practice for leading and managing Olympic teams involves the development of a vision, the management of operations, the leadership of people, and the creation of a culture" (p. 236). The NGB attempted to systematically implement an efficient, yet succinct, support structure to manage athlete stress at major international competitions with the overall goal of helping the athletes attain a very high level of success. Such focus on athlete stress has been shown to be a major factor in athlete success and a large component of how an organization fares in international competition (Fletcher \& Wagstaff, 2009).

The NGBs ultimate goal of having their athletes perform consistently at the international level left little room for subjective assessment of success. Athlete performance outcomes failed to produce consistent podium finishes in 2012. On the women's side, Americans placed in the top three on three occasions in eight international races. U.S. women finished in the top ten on nine different occasions. On the men's side, no athlete placed among the top three and only three times throughout the season did American 
men eclipse the top ten. At the Olympic Games, no American medaled. The top American female finished $4^{\text {th }}$, while the top American male finished $14^{\text {th }}$ (out of 55 in each field). These data suggest that, since 2008, performance appears to be improving somewhat on the women's side but diminishing on the men's side (Table 2)

Table 2

National Team Performance History at International Events

\begin{tabular}{|c|c|c|c|c|}
\hline & 2009 & 2010 & 2011 & 2012 \\
\hline $\begin{array}{l}\text { International Race Top } 3 \\
\text { Finishes - Men }\end{array}$ & 1 & 0 & 0 & 0 \\
\hline $\begin{array}{l}\text { International Race Top } 3 \\
\text { Finishes - Women }\end{array}$ & 0 & 0 & 2 & 3 \\
\hline $\begin{array}{l}\text { International Race Top } 10 \\
\text { Finishes - Men }\end{array}$ & 5 & 8 & 1 & 3 \\
\hline $\begin{array}{l}\text { International Race Top } 10 \\
\text { Finishes - Women }\end{array}$ & 8 & 9 & 9 & 9 \\
\hline $\begin{array}{l}\text { World Championships } \\
\text { Top } 3 \text { Finishes - Men }\end{array}$ & 0 & 0 & 1 & 0 \\
\hline $\begin{array}{l}\text { World Championships } \\
\text { Top } 3 \text { Finishes - Women }\end{array}$ & 0 & 0 & 1 & 0 \\
\hline $\begin{array}{l}\text { World Championships } \\
\text { Top } 10 \text { Finishes - Men }\end{array}$ & 1 & 0 & 0 & 0 \\
\hline $\begin{array}{l}\text { World Championships } \\
\text { Top } 10 \text { Finishes - } \\
\text { Women }\end{array}$ & 1 & 1 & 2 & 2 \\
\hline
\end{tabular}


One might question whether or not the less-than-desirable performance outcome of the NGB's athletes in 2012 was the result of the organization's inability to minimize athlete stressors. After all, Gould and Maynard (2009) found that more successful teams and athletes were able to prepare themselves mentally to deal with unexpected events and stressors. Gould and Maynard (2009) also reported that, "unsuccessful teams and athletes were found more often to deviate from plans and preparation routines at the Games" (p. 1402). Certainly, the NGB might be able to obtain increased athlete performance if it funded their High Performance program more proportionately. In many sports, money has been known to fuel championships. For example, the Miami Heat of the National Basketball Association (NBA) committed a reported \$208 million in salaries in 2010 to sign superstars LeBron James $(\$ 17.5$ million/year) and Chris Bosh (\$17.5 million/year) to join Heat veteran Dwayne Wade (\$17 million/year). In four years, the threesome led the Heat ( $\$ 84$ million total team salary payout/year) to four NBA finals appearances and two championships. With the recent success, the team is valued at $\$ 770$ million, up from $\$ 364$ million in 2009. (Forbes, 2014a). In NASCAR, Rick Hendrick fuels his five-car Sprint Cup race team with a reported \$18.6 million a year. In the past seven years, he has amassed six Sprint Cup championships (all won by driver Jimmie Johnson's car) and the value of his operation is a reported $\$ 348$ million, according to Forbes (2014b). The Los Angeles Dodgers of Major League Baseball (MLB) doubled their 2012 payroll and doled out $\$ 230$ million in player salaries in 2013 and $\$ 217$ million in 2014. The move has certainly made the Dodgers more competitive in the MLB. The New York Yankees have a history of having the highest MLB payroll, at just over \$228 million in 2014, while the Houston Astros have the league's lowest, at just over \$26 million. Records speak for themselves: the Yankees have been a perennial powerhouse; the Astros have not made it to the postseason since 2005 (Los Angeles Times, 2014).

Nonprofit organizations like NGBs are limited in their ability to generate revenue, however. Because of this, they have limited financial resources. In 2012, the USOC paid out a total of just over 
\$23 million in grants to support the athletes involved in high performance programs within its 37 summer NGBs (31 of which were Olympic programs). This direct athlete support included stipends for some athletes, health insurance, prize money for top place finishes, and tuition assistance for some of those athletes pursuing a college degree. Most athlete stipends range between $\$ 400$ and $\$ 2,000$ per month (Crumpton, 2013). The amount of funding is typically based on individual athlete results and what the USOC or NGB's performance directors deem as the athlete's potential. The USOC also awards cash incentives for athletes who medal at an Olympic Games: $\$ 25,000$ for gold, $\$ 15,000$ for silver, and $\$ 10,000$ for bronze, but these prizes are hardly the pay day athletes like LeBron James, Chris Bosh or Dwayne Wade see simply by playing a single season game.

The USOC's total expenses in 2012 were \$249 million, with \$101 million of that directed towards Sport Programming and \$74 million allotted to NGB support (United States Olympic Committee, 2014). With their allowance, each NGB has the option of paying additional athlete stipends, although the vast majority of their money is also directed towards supporting their sport programming efforts and facilitating training centers. Three priority categories determine the amount of USOC funding. In the order of those that receive the most funding, they are (a) those NGBs characterized as foundation organizations whose athletes can generate the most medals at an Olympic Games, (b) those NGBs described as medal opportunities whose athletes have a legitimate chance at earning some medals at an Olympic Games, and (c) those NGBs described as development organizations whose athletes are unlikely to medal. It is important to note, also, that NGBs, as non-profit organizations, also have the ability to generate their own additional revenue through independent sponsorships and fundraising efforts (Crumpton, 2013).

Given the additional monetary resources the NGB in this study received from the USOC prior to the 2012 Olympic Games, their athletes could be exposed with greater training opportunities, a larger array of support personnel and services, and additional stipends. Such resources could potentially attract more elite pipeline-worthy athletes to the sport, and they could further enhance 
developmental programs. But, even though none of their athletes stood atop the podium at the end of the season, NPD1 was satisfied with their overall performance of the athletes and the communication and quality of support provided to them. As evidence, he pointed to the NPDs ability to address individual differences among the athletes and meet each athlete's individual and unique needs, all while balancing the needs and chemistry of the team.

One key to success is the ability of an athlete to control his or her own response to stress. Taylor, Gould, and Rolo (2008) studied 176 members of the U.S. team at the 2000 Sydney Olympic Games and found that medalists exhibited greater emotional control and automaticity, or habitual patterning, than non-medalists. The NPDs interviewed for this study recognized the additional stress that can surround an athlete while participating in the Olympic Games. They reported a history of observing athletes under stress and understood their role in preparing athletes for "unknown" variables. The NPDs also understood their responsibility to help athletes develop coping strategies to deal with these psychological stressors. Preparing and encouraging their athletes to psychologically adapt to high-pressure situations was critical; automaticity was encouraged. Additionally, the NGBs worked to create a consistent routine for their athletes in the hopes of preventing additional (especially Olympic-related) stress.

\section{The Role of Communication}

Throughout the NGB structure, communication was stressed. Both Woodman and Hardy (2001) and Fletcher and Hanton (2003) pointed to a lack of communication between the athletes and managers as a cause of significant athlete stress, along with "perceived unfairness" in the selection process and "ambiguous selection criteria" (Fletcher \& Hanton, p. 181). Certainly, the representation of elite (including pipeline) athletes in NGB's decision-making regarding funding, travel and team selection along with the representation of the NPDs on the Athletes' Advisory Council helped to minimize some athlete stress. The four-tiered approach to communication, which stressed monthly contact between the NPDs and the athletes and their coaches, provided 
similar prevention. Similarly, the management team and athletes shared responsibility in terms of the development of the NGB's vision. This supported Fletcher and Arnold's (2011) assertion that such collective input would stimulate shared ownership within the organization (Fletcher \& Arnold, 2011).

\section{Managing Relationships/Creating Social Cohesion}

One interesting factor discussed by the participants in this study was helping athletes manage relationships. The NPDs discussed the importance of creating an environment that was socially cohesive and could help foster the development of both the individual athlete and the organization. Decreasing the stress that can inevitably hurt interpersonal relationships and have a negative effect on professional performance was also cited as an integral part of the NPDs duties (Hall, Hall \& Abaci, 1997). This finding was consistent with previous researchers who suggested the creation of the team's culture was viewed as central to effective performance leadership and management (Fletcher and Arnold, 2011). Gould and Maynard (2009) reported that, "team cohesion and harmony factors were identified by athletes and coaches as critical for Olympic success" (p. 1403). The participating NPDs placed great focus on cultivating positive relationships. These relationships consisted of those with coaches from outside the NGB and those with other athletes inside the organization.

In an attempt to help alleviate some of the stress that the athletes may have experienced while negotiating social dynamics, the NPDs described how they attempted to create a productive training and social environment for the athletes by getting to know them as individuals and also by monitoring the social situation closely while at international competitions. Further, they mentioned that they attempted to encourage athlete empathy as much as possible so that the athletes could develop a level of accountability for each other and for their training environment. These actions are in line with previous research that has suggested that coaches and leaders can positively impact the social and task cohesion of a group by getting to know athletes on a personal level as well as helping 
athletes understand their roles and responsibilities in a team environment (Weinberg \& Gould, 2010).

As noted, while the sport studied rewarded top individual placements, there were team aspects involved within racing that provided conflicting viewpoints. While researchers have reported that there is a positive level of both task and social cohesion related to performance in team-related (inter-dependent) sports (Verma, Modak, Bhukar, \& Khumar, 2012; Tziner, Nicola, \& Rizac, 2003), there is less research investigating the impact of social cohesion on the performance of individual sport (intra-dependent) sport athletes. This unique sport context can pose distinctive issues related to the issue of social cohesion. The NPDs in this study felt this was an important construct to understand. Researchers have suggested that athletes respond to organizational stressors, such as the management of athlete relationships, through a highly complex process and tend to reflect deeply upon the personal meaning of the stressors. Further, athletes can also spend valuable time and energy evaluating their resources to deal with that situation (Hanton, Christopher \& Fletcher, 2012).

\section{Supporting Structures}

While the NPDs assumed the role of surrogates on occasion, coaches external to the organization were cited as those individuals primarily responsible for the skill development of National Team athletes. It was recognized that coaches performed a critical role in athlete development, and it was also noted that those external coaches served as a source of negative stress for athletes, on some occasions. Fletcher and Arnold (2011) found that, "coaches tend to focus on improving athlete or team performance, whereas NPDs are tasked with managing logistics that enable performance development to occur" (p. 235). One of these management tasks was being able to balance the individual needs of an athlete with the goals of the organization.

Outside of helping to negotiate organizational issues and manage relationships, the NPDs interviewed for this study also suggested that they attempted to alleviate athlete anxiety related to organizational stress. These organizational stressors included 
managing training facilities on-site at competitions, helping to coordinate outside support through the provision of nutritional guidance and medical support, and organizing housing facilities that limited athlete stress. Again, this was consistent with what researchers say is important when attempting to prevent or manage stress (Gould \& Maynard, 2000). The NPDs were keenly aware of the negative impact of organizational stressors and lack of information can have on athletes and managed them as best they could.

\section{Application}

This study provided information on how NPDs of a single U.S. Olympic sport program attempted to both prevent and manage elite athletes' stress during international and Olympic competition in 2012. This is unique in that most research has looked at systemic organizational support, but not at how support is provided in a specific sport setting. The information revealed provides insight to the inner workings of NGBs, and more specifically to the roles of NPDs as it pertains to reaching organizational goals of athlete success. It may also provide other NGBs with information on how to provide similar support.

The results of this study point toward three broad applications in sport. First, while alleviating athlete stress is a systemic organizational issue that must be addressed at all levels, the people who have consistent contact with both the athletes and the organizational leaders (such as the NPDs) are those who can, often, assuage stress for athletes most effectively. These entities can do this through honest and open communication about critical issues such as the selection process, being sensitive to team and social dynamics, and by getting to know athletes on an individual level. Second, the results of this study also suggest that those who are in organizational leadership positions take seriously the communication issues that may occur and impede athlete performance. The multitiered communication approach utilized by this NGB was successfully implemented. While a limitation of this study was that athletes, themselves, were not interviewed about their sources of stress, the communication strategy used by the NPDs who had 
consistent communication with the elite athletes was deemed successful. Finally, in relation to major competitions such as national and world championships and the Olympic Games, the results of this study suggest that organizational leaders should implement a reliable and consistent support structure that includes the management of personal issues (such as travel, training, nutrition, and injury) that athletes may face during these critical contests.

\section{Suggestions for Future Research}

Based upon the findings of this study, the authors would suggest further exploration in several areas related to this research. First, given the statistics that show the lack of improved performance, the perceptions the athletes have on this specific NGB's support structures, including its NPDs ability to prevent or manage athlete stress, should be studied. Second, future research should investigate the presence and/or breadth of training National Performance Directors have received in the area of applied sport psychology. This study revealed that NPDs have a clear duty to manage athlete stress by relying a multitude of tactics. The NPDs interviewed for this study both acknowledged not having any formalized training in this area. In that absence, they said they instead relied on personal experience as elite athletes and recalling what worked well for them when they competed. Third, the SLA and NPDs involved with this study acknowledged the relative youth of its sport and the growing pressures placed upon them by the USOC to produce Olympic medal contenders. To this end, in addition to running its grassroots program, the NGB has developed a strongly supported set of developmental High Performance athlete groups who participate in elite international competition, thereby ensuring the continuation of a worthy future pipeline. The long-term benefits of allocating such resources toward development will be evident by future performance outcomes, however it would be interesting to understand the breadth of such efforts. Lastly, sport psychologists may be interested in pursuing correlational research of social/task cohesion in a mixed inter-dependent/intra-dependent sport context. 


\section{References}

Baumgartner, T. A., \& Hensley, L. D. (2006). Conducting \& reading research in health \& human performance (4th ed.). Boston: McGraw Hill. doi: 10.1111/j.1365-2206.2006.00472.x

Biddle, S., Markland, D., Gilbourne, D., Chatzisarantis, N., \& Sparkes, A. (2001). Research methods in sport and exercise psychology: Quantitative and qualitative issues. Journal of Sports Sciences, 19, 777-809. doi: $10.1080 / 026404101317015438$

Crumpton, N. I. (2013, September 18). How well are US athletes supported by the USOC? And 11 other Olympic questions. U.S. Athletic Trust. Retrieved from http://usathletictrust.org/athlete-advocacy/usatpublications/how-well-are-us-athletes-supported-by-theusoc-and-11-other-important-olympic-questions/

Duffy, P., Lyons, D., Moran, A., Warrington, G., \& McManus, C. (2006). Factors promoting and inhibiting the success of high performance players and athletes in Ireland. London, England: National Coaching and Training Centre. Retrieved from www.coachingireland.com/files/Success $\% 20$ Factors $\% 20$ STU DY.doc

Eisenhardt, K. M. (1989). Building theories from case study research. Academy of Management Review, 14(4), 532-550.

Gould, D., Flett, R., \& Bean, E. (2009). Mental preparation for training and competition. In B. Q. Brewer (Ed.), Handbook of Sports Medicine and Science: Sport Psychology (pp. 53-63). Chichester, UK: Wiley-Blackwell. doi: 10.1002/9781444303650.ch6

Gould, D., \& Maynard, I. (2009). Psychological preparation for the Olympic Games. Journal of Sports Sciences, 27(13), 13931408. doi: 10.1080/02640410903081845

Fletcher, D., \& Arnold, R. (2011). A qualitative study of performance leadership and management in elite sport. Journal of Applied Sport Psychology, 23, 223-242. doi: 10.1080/10413200.2011.559184 
Fletcher, D., \& Hanton, S. (2003). Sources of organizational stress in elite sports performers. The Sport Psychologist, 17, 175-195. Retrieved from http://www.sportmanagement.ca/docs/447/Sources_of_Organ izational_Stress.pdf.

Fletcher, D., \& Wagstaff, C. R. (2009). Organizational psychology in elite sport: Its emergence, application and future. Psychology of Sport and Exercise, 10(4), 427-434. doi: 10.1016/j.psychsport.2009.03.009

Forbes. (2014a, January). NBA team evaluations: Miami Heat. Retrieved from http://www.forbes.com/teams/miami-heat/.

Forbes. (2014b, February 20). The most valuable Nascar teams. Retrieved from http://www.forbes.com/sites/kurtbadenhausen/2014/02/20/the -most-valuable-nascar-teams/.

Hall, E., Hall, C., \& Abaci, R. (1997). The effect of human relations training on reported teacher stress. British Journal of Educational Psychology, 67(1), 483-496. doi: 10.1111/j.2044-8279.1997.tb01260.x

Hanton, S. (2011). The psychosocial dynamics of organizational effectiveness: Common themes throughout the mainstream and sport literatures [Supplement]. Journal of Sport and Exercise Psychology, 23, S180.

Hanton, S., Christopher, R. D., \& Fletcher, D. (2012). Cognitive appraisal of stressors encountered in sport organizations. International Journal of Sport and Exercise Psychology, 10(4), 276-289. doi: 10.1080/1612197X. 2012.682376

Hanton, S., Wagstaff, C.R.D, \& Fletcher, D. (2007). Cognitive appraisal of stressors encountered in sport organizations [Supplement]. Journal of Sport and Exercise Psychology, 29, S167-S168.

Ioana, A. C., Vasilica, G., Alin, L.,, \& Iulian, A. D. (2012). Sport and performance: The relationship between competition stress and biological reactions in practicing performance in athletics. Ovidus University Annals, Series Physical Education \& Sport/Science, Movement \& Health, 12(1), 510 . 
Kristiansen, K., \& Roberts, G. C. (2010). Young elite athletes and social support: Coping with competitive and organizational stress in "Olympic" competition. Scandinavian Journal of Medicine and Science in Sports, 20, 686-695. doi: 10.1111/j.1600-0838.2009.00950.x

Lee, S., Christopher, R. D., Fletcher, D., and Hanton, S. (2007). The psychological dynamics of organizational effectiveness: Common themes throughout the mainstream of sport literatures. Journal of Sport \& Exercise Psychology, 29, S180.

Los Angeles Times. (2014, June 10). Can money buy baseball glory? Retrieved from http://graphics.latimes.com/mlbsalaries/\#dodgers:angels.

Patton, M. Q. (2000). Qualitative evaluation and research methods ( $2^{\text {nd }}$ ed.). Newbury Park, CA: Sage. doi: 10.1002/ nur.4770140111

Richard, P. J., Devinney, T. M., Yip, G. S. \& Johnson, G. (2009). Measuring organizational performance: Towards methodological best practice. Journal of Management, 35(3), 718-804. doi: 10.1177/0149206308330560

Shirom, A. (1982). What is organizational stress? A facet analytic conceptualization. Journal of Occupational Behavior, 3, 21 37. doi: $10.1177 / 001872678804100404$

Silk, M. L., Andrews, D. L., \& Mason, D. S. (2005). Encountering the field: Sports studies and qualitative research. In D. L. Andrews, D. S. Mason, and M. L. Silk (Eds.), Qualitative Methods in Sports Studies (pp. 1-20). Oxford, New York: Berg.

Taylor, M. K., Gould, D., \& Rolo, C. (2008). Performance strategies of U.S. Olympians in practice and competition. High Ability Studies, 19, 15-32. doi: 10.1080/13598130801980281

Thomas, G. (2011). A typology for the case study in social science following a review of definition, discourse and structure.

Qualitative Inquiry, 17(6). 511-521. doi: $10.1177 / 1077800411409884$ 
Tziner, A., Nicola, N., \& Rizac, A. (2003). Relation between social cohesion and team performance in soccer teams. Perceptual and Motor Skills, 96(1), 145-148. doi: 10.1146/annurev.cellbio.24.110707.175350

United States Olympic Committee (2014). Team USA: Finance. Retrieved from http://www.teamusa.org/Footer/Finance

Verma, J. P., Modak, P., Bhukar, J. P., \& Kumar, S. (2012). A discriminant analysis of team cohesiveness among highperformance and low-performance elite Indian volleyball players. Studies in Physical Culture and Tourism, 19(4), 191195.

Weinberg, R. S. \& Gould, D. (2010). Foundations of sport and exercise psychology $\left(5^{\text {th }}\right.$ ed.). Champaign, IL: Human Kinetics. doi: 10.1080/17461391.2011.568631

Woodman, T., \& Hardy, L. (2001). A case study of organizational stress in elite sport. Journal of Applied Sport Psychology, 13, 207-238. doi: 10.1080/ 104132001753149892

Yin, R. K. (2003). Case study research: Design and methods $\left(3^{\text {rd }}\right.$ ed.). Thousand Oaks: CA: Sage. doi: 10.1046/j.13652648.2003.02790_1 
The Journal of SPORT, 2014, 3(2), 184-202

(C) Kent State University

Title IX Proportionality Prong: Compliance of Division I FBS Universities

\author{
Laura Simon \\ Ball State University \\ Shannon T. Dieringer \\ Ball State University \\ Elizabeth Wanless \\ Ball State University \\ Rebecca M. Tyner \\ Reston, $\mathrm{Va}$ \\ Lawrence W. Judge \\ Ball State University
}




\begin{abstract}
Title IX of the Education Amendments Act of 1972 (Title IX), enacted to protect individuals from discrimination based on gender in educational programs, is enforced by the Office for Civil Rights, In regard to collegiate sport, the enactment of Title IX has resulted in increased opportunities; however, sport organizations frequently fail to meet compliance with proportionality. The purpose of this study is to examine the compliance of Division I Football Bowl Subdivision (FBS) conference schools with the proportionality prong of the Title IX test. Results suggest that data from 2011-2012 for total athletes in all FBS conferences $(\mathrm{M}=4.59, \mathrm{SD}=4.39)$ was significantly different from data in $2005(\mathrm{M}=9.2), \mathrm{N}=11, \mathrm{t}=-3.488$, $\mathrm{p}=0.006$. Additionally, data for unduplicated athletes $(\mathrm{M}=7.23$, $\mathrm{SD}=4.63)$ was not significantly different from data in $2005(\mathrm{M}=9.2)$, $\mathrm{N}=11, \mathrm{t}=-1.416, \mathrm{p}=0.187$. The actual number of Division I athletes, reflects no significant change in the proportionality gap since 2005 . A positive correlation was found between female undergraduate percentage and the proportionality gap with total athletes $(r=0.760$, $p=0.007, \alpha \leq .05)$ and an even stronger positive correlation between female undergraduate percentage and the proportionality gap with unduplicated athletes $(\mathrm{r}=.0858, \mathrm{p}=.001, \alpha \leq .05)$. Although changes are being made to improve gender equity within Division I, on-going consideration is needed of additional opportunities to improve gender equity in collegiate sports.
\end{abstract}




\section{Introduction}

The success of collegiate athletic teams often unites the student body, faculty, and alumni through a sense of camaraderie. Furthermore, the feeling of belonging is shared between and among teammates and supporters, which creates a sense of belonging is influential in ensuring success during the collegiate experience and beyond. For example, participation in organized sports provides opportunities to succeed in the workforce (e.g., networking, understanding personal and interpersonal relationships, and exposure to job opportunities) (Boxill, 1993). However, recent figures suggest that fewer females participate in Division I sports when compared to their male peers (Irick, 2011). To help ensure equality between males and females, Title IX of the Education Amendments of 1972 was enacted to protect individuals from discrimination based on gender in educational programs that receive federal funding (including interscholastic sports).

\section{The History of Title IX}

Title IX is enforced by the Office for Civil Rights (OCR), which was formed in 1980 after the Department of Health, Education and Welfare was eliminated and currently resides within the Department of Education. Congress passed Title IX in 1972 in response to the need for equality within an educational setting. Title IX states:

"No person in the United States shall, on the basis of sex, be excluded from participation in, be denied the benefits of, or be subjected to discrimination under any education program or activity receiving Federal financial assistance" (U.S. Department of Education, 1972).

Although the intent of Title IX to include equity in sport was widely accepted (Rishe, 1999), the vagueness of the passage led to questions regarding its implications; resulting in delayed implementation.

In 1974, the U.S. Department of Health, Education, and Welfare (HEW) published draft regulations to Title IX for public comment. These regulations were developed in order to assist organizations in their efforts to comply with the law through the provision of a thorough explanation of Title IX. The draft 
regulations confirmed that collegiate sports were also subject to Title IX requirements. In response, the National Collegiate Athletics Association (NCAA) and the College Football Coaches Association (CFCA) opposed the application to athletics (Ridpath et al., 2009). However, because Title IX mandated equal educational opportunities, oppositions of educational institutions were denied (Ridpath et al., 2009).

From 1975 to 1979, numerous complaints were filed with HEW concerning noncompliance in universities. Continued inconsistencies with interpretation of Title IX prompted the HEW to issue a 1978 proposed interpretation of the policy, which went into effect the following year (U.S. Department of Education, 1979). While the program was aimed to address 13 different programs, one area was developed to ensure that athletics was appropriately meeting the HEW's policy. Title IX was instated to ensure that all students were receiving equal and effective accommodations to their interests and abilities. The interpretation included a three-pronged test used in determining compliance. The test required federally funded institutions to meet at least one of the compliance standards. The three-prong test included: a) substantial proportionality providing opportunities for participation in intercollegiate sports by gender in approximate proportion to undergraduate enrollment; b) continued expansion - demonstrating a history of a continuing practice of expanding opportunities for the underrepresented gender; and c) full accommodation - presenting proof that the university fully and effectively accommodates the athletic interests of the underrepresented gender (U.S. Department of Education, 1979). Demonstration of compliance in one or more areas was considered to be sufficient in meeting Title IX. The 1978 interpretation provided the guidance needed to more fully understand the requirements of the law.

Due to political pressure and multiple investigations brought against universities regarding Title IX, additional clarification was required to properly enforce the law. In 1996, The Office for Civil Rights (OCR) issued another clarification of the law. The OCR's interpretation of substantial proportionality stated that proportionality would be achieved "when the number of 
opportunities that would be required to achieve proportionality would not be sufficient to sustain a viable team" (OCR, 1996, p. 5). Further explanation for continued expansion stated that there were no fixed intervals of time or required number of additional teams needed to demonstrate compliance, and the OCR provided general descriptions of evidence that could be used to demonstrate compliance (OCR, 1996). For full accommodation, OCR made clarifications that there cannot be compliance when there is sufficient interest in a team, ability to sustain a team, and an expectation of competition for a team that is not yet offered (OCR, 1996). OCR also stated which type of data they would use to determine compliance for full accommodation and permitted schools to assess interests of the underrepresented gender (OCR, 1996). In 2005, OCR released additional clarification for full accommodation, which explained that schools were allowed to use a web-based prototype survey to assess athletic interests on campus (OCR, 2005). The 2005 clarification was later overturned in 2010 by the Obama administration (Barnett \& Hardin, 2010).

\section{Addressing issues of noncompliance with Title IX.}

Since the inception of Title IX and the OCR's involvement with ensuring compliance, opportunities for female athletes to participate in collegiate sport have increased. However, the requirements included in the substantial proportionality are rarely met, and continues to be a significant concern. Proportionality, according to the three-part test, is met by providing opportunities in intercollegiate sport, by gender, in approximate proportion to undergraduate enrollment (U.S. Department of Education, 1979). One of the main issues for colleges was defining "approximate proportion" specific to the school in question. The notion of approximate proportion may vary based upon the specifics of that particular school.

\section{The impact of male sports on Title IX compliance (student ratio and roster size).}

One contributing factor to the significant disproportionality is that there is no single women's sport that has a roster size close to that of football (Rishe, 1999). As such, women's rowing provides 
the largest roster size, which includes approximately 60 female athletes compared to approximately 100 male athletes on the football roster. Although women's rowing teams do provide an opportunity for female athletes to participate, few schools have the financial support (as rowing is very expensive) to support such athletic teams. Therefore, it is unlikely that women's rowing is a solution to the proportionality argument, as there is still at least a $40 \%$ participation gap even with the availability of rowing. Furthermore, due to the rulings on 'proportion' schools with a larger number of female undergraduates will likely find it even more difficult to demonstrate compliance (Anderson et al., 2006). The result is that many schools will remain out of compliance according to substantial proportionality.

In 2005-2006, at Division I Football Bowl Subdivision schools (FBS), men's athletics accounted for $70 \%$ of total expenses; in Division I Football Championship Subdivision schools (FCS), men's athletics accounted for $61 \%$ of overall expenses; in NCAA Division I schools without a football program, men's athletics accounted for 52\% of overall expenses (Women's Sports Foundation, 2009). In 2005-2006, NCAA Division I schools, on average, expended more total funds on football programs $(\$ 5,740,000)$ than on all women's teams combined $(\$ 4,447,900)$ (2005-2006 Gender Equity Report). When considering the cost of football and the large numbers of male athletes, some may argue that football presents significant barriers to Title IX compliance. Advocates of Title IX claim that proportionality can be reached if universities were more diligent with resources. However, some advocates believe that reducing the resources allocated for football would open up other opportunities for both male and female athletes.

The pressures placed on universities to demonstrate Title IX compliance resulted in officials seeking alternative ways to bridge the proportionality gap. One solution included reducing men's sports in an effort to neutralize the discrepancy. In 2011, 26\% of coaches surveyed expressed a concern that Title IX was being used to eliminate or reduce men's sports (Staurowsky and Weight, 2011). Between 1995 to 2005 there were increases in both collegiate men and women sport participation (7,000 and 25,000 participant 
increase respectively) (Cheslock, 2007). Although there were increases in collegiate sport participation for both men and women, men's collegiate sport teams were eliminated in some schools (Cheslock, 2007 \& Leung, 2009). However, the reasons behind these reductions are up for debate. Even with the apparent decrease in the numbers of male athletes, trends in spending over the past five years indicate that approximately half of collegiate athletic dollars are spent on men's sports (U.S. Department of Education, 2012). The Knight Commission has reviewed the high cost of athletic programs, finding that the continuing rise in costs is not sustainable (The Knight Commission, 2011).

\section{Roster management.}

Accuracy in reporting of rosters has been a concern for many years, yet is infrequently discussed. Inaccurate reporting of roster numbers could be used to address the proportionality issues that often plague universities' compliance with Title IX. The concept known as 'padding rosters' comes into play when universities count one female athlete as two separate athletes when that athlete happens to participate in two different sports. Additionally, schools may pad rosters by mis-identifying who is on the team. For example, if the women's basketball team has 8 men who are on the practice squad, the university may include those 8 male athletes on the roster's total number of participants, resulting in roster padding (Colleges lie about Title IX compliance: Report. The Huffington Post. 2011).

Although the United States has taken steps to bridge the proportionality gap, opportunities for growth continue to present themselves. Title IX has played a significant role in this increase of female athletes throughout the past four decades, and has greatly impacted intercollegiate sports (Cheslock, 2007). The number of female athletes has risen dramatically in collegiate sports. In 1982, 73,742 men and 26,461 women played Division I college sports, and in 2011 the number had raised to 91,013 men and 78,024 females respectively (Irick, 2011). Similar results were noted in high school athletics as the numbers of female participation increased to over 2.8 million by 2002 (Carpenter \& Acosta, 2005). Despite these improvements, general equality between males and females is not yet commonplace in sports or in our society. Due to the subjective 
nature of continued expansion and full accommodation, substantial proportionality may be the only true way to demonstrate compliance with Title IX policy of equality. The purpose of this study is to examine the compliance of Division I FBS conference schools with the proportionality prong of the Title IX test.

\section{Research Questions}

The following research questions guided this study:

1. To what extent do NCAA Division 1 conferences meet the $6 \%$ threshold of proportionality? How do NCAA Division I conferences comply with Title IX proportionality?

2. How does the current average proportionality gap for NCAA Division I universities compare to the average proportionality gap in 2005?

3. Is there a correlation between compliance to Title IX and the number of undergraduate students enrolled at the university?

For research question one, it was hypothesized that the Southeastern Conference (SEC) would be in lower compliance than other schools because they are reported to be the highest spenders per athlete when compared to all Division IA universities (Gregory, 2013). For question two, it was hypothesized that average proportionality gap would be smaller when compared to 2005. For research question three, it was hypothesized that larger enrollment rates make it more difficult to demonstrate compliance with Title IX because larger enrollments would require greater allocation of resources for women's athletics.

\section{Methodology}

Prior to the start of the study, the researcher assessed page content and features of NCAA Division I FBS sport websites. The Equity in Athletics Data Analysis website (U.S. Department of Education, 2012b) and the National Center for Education Statistics (U.S. Department of Education, 2012a) were independently reviewed during a two-week period in February of 2013. The twoweek timeframe was determined to be of sufficient length to obtain 
meaningful data through a snapshot approach, which is consistent with the exploratory nature of the study. The current research was a descriptive study using secondary data; therefore, it was not necessary to obtain informed consent.

A purposeful sample was chosen in order to identify schools that may be subject to closer scrutiny related to Title IX in athletics. The participants in this study were 128 universities from the FBS which include the following conferences and the number of corresponding schools as members: ACC-12, SEC-12, Big Ten-12, Big 12-10, Big East-16, Conference USA-12, WAC-10, MAC-13, Mountain West-7, Sun Belt-12, and Pac 12-12. All schools that were members of one of these conferences during 2011-12 were used in the study. The schools consist of a combination of public and private universities across the United States.

\section{Procedures}

To begin data collection, an initial excel file was created with a separate sheet made for each conference. For each specific conference, the schools' names were added to the left side of the page. To the right of each school's name, there was a column for male undergraduate percentages and female undergraduate percentages. On the top of each sheet, room was left to put in the grand total of female and male athletes in the conference and the unduplicated number of female and male athletes from each conference provided by the Equity in Athletics Data Analysis website (U.S. Department of Education, 2012b).

Once the data was entered for each conference, the schools' average enrollment rates for each conference were calculated. These statistics were obtained from the U.S. Department of Education (2012a). The average proportionality gap was found by subtracting the percentage of female athletes from the percentage of female undergraduate students.

\section{Data Analysis}

Descriptive statistics were generated for the variables included in this study to determine whether or not an aggregate of the data of the schools in each conference met the 5\% standard. A 
paired-samples t-test was used compare the means of two data points (2005-6 and 2011-12) to detect whether there were any statistically significant differences. A modern statistical software package was used to perform the analysis (SPSS ver 17.0) and statistical significance was set a priori at alpha $<0.05$.

\section{Results}

Seven of the 11 conferences that were used in the study were in compliance with Title IX in 2011-12 when using the grand total of athletes for each conference. However, when looking at the unduplicated number of athletes for each conference, only three of the 11 conferences were in compliance with Title IX. Table 1 lists data for each conference, including; the mean for total athletes and unduplicated athletes as well as undergraduate enrollment rates. The three conferences with the lowest level of policy compliance were Sun Belt (Total Athletes (TA) $=15.18$, Unduplicated Athletes $(\mathrm{UA})=17.77)$, Conference USA $(\mathrm{TA}=9.52, \mathrm{UA}=12.21)$, and SEC $(\mathrm{TA}=5.47, \mathrm{UA}=7.86)$. The three conferences with the best compliance were Big Ten $(\mathrm{TA}=0.18, \mathrm{UA}=1.49)$, Big $12(\mathrm{TA}=1.00$, $\mathrm{UA}=2.39)$, and $\mathrm{WAC}(\mathrm{TA}=1.04, \mathrm{UA}=5.28)$. 
Table 1

Average Proportionality Gap of conferences in the FBS

\begin{tabular}{lccccc}
\hline Conference & $\mathrm{N}$ & $\begin{array}{c}\text { Ave. } \\
\text { Prop. } \\
\text { Total } \\
\text { Athletes }\end{array}$ & $\begin{array}{c}\text { Ave. Prop. } \\
\text { Unduplicated }\end{array}$ & $\begin{array}{c}\text { Male } \\
\text { Undergrad }\end{array}$ & $\begin{array}{c}\text { Female } \\
\text { Undergrad }\end{array}$ \\
\hline Big Ten & 12 & 0.18 & 1.49 & 51.4 & 48.6 \\
ACC & 12 & 4.10 & 6.30 & 51.2 & 48.8 \\
SEC & 12 & 5.47 & 7.86 & 48.3 & 51.7 \\
Big East & 16 & 3.00 & 5.40 & 47.7 & 52.3 \\
Big 12 & 10 & 1.00 & 2.39 & 50.7 & 49.3 \\
Conference USA & 12 & 9.52 & 12.21 & 45.3 & 54.7 \\
MAC & 13 & 5.07 & 8.67 & 47.1 & 52.9 \\
Mountain West & 7 & 3.90 & 8.10 & 45.4 & 54.6 \\
Sun Belt & 12 & 15.18 & 17.77 & 42.5 & 57.5 \\
Pac 12 & 12 & 2.01 & 4.00 & 49.8 & 50.2 \\
WAC & 10 & 1.04 & 5.28 & 46.3 & 53.7 \\
\hline Total/Average & $\mathbf{1 2 8}$ & $\mathbf{4 . 5 8 8 2}$ & $\mathbf{7 . 2 2 4 5}$ & $\mathbf{4 7 . 7 9 1}$ & $\mathbf{5 2 . 2 0 9}$ \\
\hline
\end{tabular}

Note. Ave. Prop. $=$ Average Proportionality is a percentage. Acceptable percentage is $\leq \mathbf{5}$. Undergrad $=$ Undergraduate enrollment rate as a percentage.

In 2005, the average proportionality gap of all Division I universities was $9.2 \%$ (Cheslock, 2007). A t-test ( $\alpha \leq .05)$ revealed that data from 2011-2012 for total athletes in all FBS conferences $(\mathrm{M}=4.59, \mathrm{SD}=4.39)$ was significantly different from data in 2005 $(\mathrm{M}=9.2), \mathrm{N}=11, t=-3.488, p=0.006$. Another $\mathrm{t}$-test $(\alpha \leq .05)$ revealed that data for unduplicated athletes $(\mathrm{M}=7.23, \mathrm{SD}=4.63)$ was not significantly different from data in $2005(\mathrm{M}=9.2), \mathrm{N}=11, t=-1.416$, $p=0.187$.

Review of the correlation between the female undergraduate percentage and the proportionality gap found that there was a positive correlation between female undergraduate percentage and 
the proportionality gap with total athletes $(\mathrm{r}=0.760, \mathrm{p}=0.007$, $\alpha \leq .05$ ), and there was also a stronger positive correlation between female undergraduate percentage and the proportionality gap with unduplicated athletes $(\mathrm{r}=0.858, \mathrm{p}=.001, \alpha \leq .05)$.

\section{Discussion}

The results of this study warrant continue to highlight the need for attention from professionals in collegiate athletics and provide insight regarding three specific research questions. The first research question investigated how NCAA Division I conferences compare with Title IX proportionality. According to the present study, data from the 2011 unduplicated number of participating athletes indicate that only three of Division I FBS conferences were in Title IX compliance. The hypothesis that SEC conference schools would be in lower compliance than other schools was supported given the above results. Therefore, the issues surrounding proportionality and spending allocated for male versus female athletic teams remains concerning. The results of the analysis of Title IX compliance in the present study were more closely related to athletic department budgets rather than geographic location.

When analyzing Title IX compliance with regards to athletic department budgets, the FBS can be further divided into Bowl Championship Series (e.g., Southeastern, Big 12, Pacific 10, Atlantic Coast, Big East (now American), and Big Ten) and Non-BCS (Conference USA, Mid-American, Mountain West, Sun Belt, and Western Athletic) conferences. The sports media term "BCS conference" refers specifically to the members of the six conferences whose champions received an automatic berth in one of the five BCS bowl games. To bring further concern to the issue, the American Institutes for Research released a report in early 2013 which stated that the BCS or power conferences for athletics reported spending as much as $\$ 100,000$ per athlete in 2010 which was at least six times the amount the university was spending for academics (Derochers, 2013). Furthermore, the FBS universities competing in the top tier conferences for Football, known as the BCS, spent over $\$ 92,000$ per athlete compared to the $\$ 37,000-\$ 39,000$ spent per athlete enrolled in Division I schools not in the BCS (American Institutes for 
Research, 2013). This data suggest that budgets are often allocated to the larger more male dominated sports (i.e. football and basketball) rather than equally across the universities' entire athletic department and sports. The gap in spending for athletics between FBS universities in the BCS conferences versus other Non-BCS conferences suggests that proportionality may not be as accurately reported.

As such, the two FBS conferences with the lowest level of compliance were the non-BCS conferences of the Sun Belt and Conference USA. The members of these conferences have modest budgets compared to their BCS counterparts. While, the two conferences with the highest level of Title IX compliance were the BCS conferences of the PAC 12 and Big 10.

The second research question compared the current average proportionality gap for NCAA Division I schools to the average in 2005. Data revealed that there was a significant change from 2005 to 2011 in terms of proportionality in Division I schools, but only for the data where some athletes were counted twice as participants (padding rosters). During this time, the proportionality gap decreased by 4.61 percentage points. Upon further investigation, when examining the actual number of athletes, and not the total number of athletes, the gap only decreased 1.97 percent, which is not a significant difference from 2005. These results cannot be generalized to all Division 1 universities because only data from the FBS schools were used. These results verify that within a six-year period, changes have been made within Division I universities in order to move towards compliance. Despite effective change, the data indicates that there continues to be opportunity for improvement. Over the past five years, schools in the NCAA's top six sport conferences raised more than $\$ 3.9$ billion for new sport facilities, according to the Chronicle of Higher Education (Wolverton, 2007), and are using the money to build or upgrade stadiums, training facilities, offices, and meeting rooms. The reported spending reflects an understanding that these facilities are a powerful recruiting tool because it demonstrates that the university cares enough about the athletes to put money into facilities that are not even visible to spectators (Suggs, 2003). The data presented in this study provides the current status of Title IX 
compliance of NCAA FBS institutions and demonstrates the designation of resource allocation.

The third research question investigated the relationship between Title IX compliance and undergraduate enrollment rates. Using results from this study, it was determined that enrollment does have some impact on the compliance of Title IX. When examining the correlation between the female undergraduate percentage and the proportionality gap, it was discovered that there was a positive correlation between female undergraduate percentage and the proportionality gap with total athletes $(\mathrm{r}=0.760, \mathrm{p}=0.007, \alpha \leq .05)$ and an even stronger positive correlation between female undergraduate percentage and the proportionality gap with unduplicated athletes $(\mathrm{r}=.0858, \mathrm{p}=.001, \alpha \leq .05)$. As a school's female enrollment rate increases, it becomes even more difficult for the school to achieve compliance through the proportionality prong.

Limitations. The first limitation is that only FBS schools were used in the sample population. If all Division I universities were included in the study, results may have been different due to potential variations in budget size if additional universities were included. Another limitation is that researchers made an assumption that all universities reported their enrollment rate correctly to the U.S. Department of Education. If the enrollment data was incorrectly reported then, the proportionality data could be misrepresented. Additionally, the potential for inaccuracy of data reporting, through roster padding, may also serve as a limitation. The final limitation is the possibility of human error as the researcher imputed data into excel and SPSS and calculated the results.

\section{Conclusion}

The full assimilation of women in the sports industry has not yet been realized, which mirrors the current societal norms. The importance of Title IX compliance for colleges and universities in the United States is well established and a renewed focus regarding gender equity is both justified and necessary. A university's status determines its success in attracting the top recruits and quality student-athletes. FBS universities are generally the most popular, well known, and have the largest athletic budgets. 
As the financial stakes of intercollegiate athletics continue to increase, university athletic programs continue to seek opportunities to attract higher caliber athletes and develop these athletes to reach their peak potential within the span of their eligibility. The competition to attract high caliber student-athletes has many similarities to an arms race where high quality facilities and programs for both competition and training can become weapons in the recruiting battle. But the arms race in collegiate athletics may have impacted progress towards Title IX compliance. In 2010, only $20 \%$ of FBS athletic departments created positive revenue without help from the university or state funds (Brady, Upton, \& Berkowitz, 2011). One can only speculate on how the arms race in collegiate athletics has impacted. However, Title IX compliance policy regulations continue to be a necessary benchmark to achieve institutional goals. A coordinated approach to include additional opportunities for women in collegiate sport will be a significant step toward reaching Title IX compliance. The addition of women's sports would provide women with new opportunities to participate. The reduction of men's sports in order to become more compliant does not further the initiative. Rather, the reduction of men's sports simply reduces opportunities for men without increasing opportunities for women. Although the reduction may result in data which looks better on paper, the situation has not changed.

The results of this study reflect a need for future investigations to identify effective solutions to disproportionality. One possible solution may include the reallocation of resources in an effort to add women's teams in order to become Title IX compliant. The biggest drastic change that would really impact the issue of disproportionality would be offering high school girls and collegiate women the opportunity to play football. But, this concept may take years to come to fruition. It may also be important to compare data across divisions to determine whether similar issues of noncompliance exist in all divisions. Although Title IX has played an important role in strengthening the opportunities for female athletes, there continues to be a need for deep rooted change; change which not only brings about compliance with Title IX, but also becomes a 
catalyst for societal change which facilitates full assimilation of female athletes into collegiate sports. 


\section{References}

Anderson, D. J., Cheslock, J. J., \& Ehrenberg, R. G. (2006). Gender equity in intercollegiate athletics: Determinants of Title IX compliance. The Journal of Higher Education, 77(2), 225250 .

Barnett, B., \& Hardin, M. C. (2010). Advocacy from the liberal feminist playbook: The framing of Title IX and women's sports in news releases from the women's sports foundation. International Journal of Sport Communication, 3, 178-197.

Boxill, J. (1993). Title IX and gender equity. Journal of the Philosophy of Sport, 20-21(1), 23-31.

Brady, E., Upton, J., \& Berkowitz, S. (2011, November 17). Coaches' pay soars again. USA Today, pp. 1A-2A, 5C. Carpenter, L. J., \& Acosta, R. V. (2005). Title IX. Champaign, IL: Human Kinetics.

Cheslock, J. (2007). Who's Playing College Sports? Trends in Participation. East Meadow, N.Y.: Women's Sports Foundation.

Derochers, D., M. (2013). Academic spending versus academic spending: Who wins? Delta Cost Project at the American Institutes for Research. Retrieved from http://keepingscore.blogs.time.com/2013/01/17/athleticsover-academics-the-growing-college-sports-spending-gap/.

Gregory, S. (2013, January 17). Athletics over academics: The growing college sports spending gap. [web article]. Retrieved from http://keepingscore.blogs.time.com/2013/01/17/athleticsover-academics-the-growing-college-sports-spending-gap/.

Irick, E. (2011). NCAA sports sponsorship and participation rates report. Retrieved from http://www.ncaapublications.com/productdownloads/PR2012 .pdf 
Leung, R. (2009, February 11). The battle over Title IX. Retrieved from http://www.cbsnews.com/stories/2003/06/27/60minutes/main 560723.shtml

NCAA, 2005-06 Gender-Equity Report. Retrieved from http://www.ncaapublications.com/p-3849-2005-06-ncaagender-equity-report.aspx

Office for Civil Rights (1996). Clarification of Intercollegiate Athletics Policy Guidance: The Three-Part Test. Washington, D.C.: U.S. Department of Education. Retrieved from http://www2.ed.gov/about/offices/list/ocr/docs/clarific.html

Office for Civil Rights (2005). Additional Clarification of Intercollegiate Athletics Policy: Three-Part Test-Part Three. Washington, D.C.: U.S. Department of Education. Retrieved from http://www2.ed.gov/about/offices/list/ocr/title9guidanceFinal .html

Ridpath, B. D., Yiamouyiannis, A., Lawrence, H., \& Galles, K. (2009). Changing sides: The failure of the wrestling community's challenges to Title IX and new strategies for saving NCAA sport teams. Journal of Intercollegiate Sports, 1(2), 255-283.

Rishe, P. J. (1999). Gender gaps and the presence and profitability of college football. Social Science Quarterly, 80(4), 702-717.

Staurowsky, E. J., \& Weight, E. A. (2011). Title IX literacy: What coaches don't know and need to find out. Journal of Intercollegiate Sport, 4, 190-209.

Suggs, W. (2003). Sports as the university's front porch? The public is skeptical. The Chronicle of Higher Education, 49(34), A17.

The Associated Press. (2011, April 26). Colleges lie about Title IX compliance: Report. The Huffington Post. Retrieved from http://www.huffingtonpost.com/2011/04/26/colleges-lieabout-title-_n_853659.html

The Knight Commission. (2011). Retrieved from http://www.knightcommission.org/ 
U.S. Department of Education. (1972). Title IX of the Education Amendments (20 U.S.C. $\S 1681-1688$ ). Retrieved from http://www.dol.gov/oasam/regs/statutes/titleix.htm

U.S. Department of Education. (1979). A Policy Interpretation: Title IX and Intercollegiate Athletics (44 Fed. Reg. (to be codified at 45 C.F.R. pt. 26)). Retrieved from http://www2.ed.gov/about/offices/list/ocr/docs/t9interp.html

U.S. Department of Education. (2012a). National center for education statistics. Retrieved from http://nces.ed.gov/globallocator/

U.S. Department of Education. (2012b). The equity in athletics data analysis cutting tool. Retrieved from http://ope.ed.gov/athletics/index.aspx

Wolverton, B. (2007, September 25). Sharp growth in athletics fund raising leads to decline in academic donations on some campuses. Chronicle of Higher Education, 54(6).

Women's Sports Foundation. (2009). Women's sports \& fitness facts $\&$ statistics. Retrieved from

http://www.womenssportsfoundation.org/home/research/artic les-and-reports/athletes/womens-sports-facts

Women's Sports Foundation. (n.d.) Dropping men's sports- The Division I football/basketball arms race is the culprit in the cutting of men's Olympics sports. Retrieved from http://www.womenssportsfoundation.org/home/advocate/title -ix-and-issues/title-ix-

positions/football_basketball_arms_race 
The Journal of SPORT, 2014, 3(2), 203-220

(C) Kent State University

\section{Cross Cultural Differences in Consumer Evaluation of} Cobranding in Sport

Donghun Lee

University of Houston

\section{David Pierce}

Indiana University-Purdue University Indianapolis

Kyung-O Kim

Kyungil University

Chelsie Krill

Ball State University

Nathan Felver

Ball State University 


\begin{abstract}
Brand evaluation has been studied from a cross-cultural context in recent years (Monga \& John, 2007). As a potential reason for individual differences in brand evaluations, Nisbett et al. (2001) indicated that eastern cultures generally promote holistic thinking while Western societies generally promote analytic thinking. Based on the premise of different styles of thinking, the current study examined how varying aspects of brand fit evaluation and attitude toward cobranded products impact an individual's purchase intention of cobranded products from a cross-cultural perspective. Using individuals who frequently purchase team merchandise (160 Americans and 162 Asians), two separate multiple linear regressions were performed and the overall results indicated that Americans were more likely to be influenced by brand image fit, brand quality fit, and attitude related to purchase intention of cobranded sports merchandise. In contrast, Asians were more influenced by brand quality fit, brand functionality fit, and attitude for their purchase intention. Findings from this type of research would provide practitioners and scholars with marketing insights related to how individuals evaluate cobranding practices and how cultural differences impact results in differing brand extension evaluations among global consumers of athletic team merchandise.
\end{abstract}


Brand evaluation has been studied from a cross-cultural context in recent years (Keller \& Aaker, 1992; Loken \& John, 1993; Nisbett, Peng, Choi, \& Norenzayan, 2001; Monga \& John, 2004, 2007; Yoon \& Gurhan-Canli, 2004). Brand extension is a marketing strategy used by firms to produce a product with a well-developed image using the same brand name in a different product category (Aaker \& Keller, 1990). For example, Nike recently launched Nike Plus to extend its existing product class by capitalizing its brand recognition. Cobranding, also known as dual branding (Levin, 2002) or brand alliance (Walchli, 2007), is slightly different from brand extension, and is defined as the practice of a product featuring more than one brand (Hillyer \& Tikoo, 1995). An example of cobranding in sport is Nike and Apple or Adidas and Samsung producing a wireless sensor compatible with devices such as the iPod that can track workouts for fitness enthusiasts. Lee, Kroncke, and Johnson (2012) pointed out that in the context of sport, cobranding occurs in the form of product licensing partnerships such as athletic team merchandise. They argued that "treating this type of dual branding practice as a mere licensing agreement is a myopic thinking because marketers use cobranding tactics to reposition perceptions of products, leverage consumer brand evaluations, which will ultimately contribute in increasing product sales" (p. 161).

Researchers have consistently found that cross-cultural variations exist in brand extension evaluations due to differing styles of thinking. Two paradigms, holistic and analytic thinking, explain this important consumer behavior concept. More specifically, Nisbett et al. (2001) indicated that eastern cultures often promote holistic thinking, defined as "involving an orientation to the context or field as a whole, including attention to relationships between a focal object and the field, and a preference for explaining and predicting events on the basis of such relationships" (p. 293). In contrast, Western societies often promote analytic thinking, defined as "involving detachment of the object from its context, a tendency to focus on attributes of the object to assign it to categories, and a preference for using rules about the categories to explain and predict the objects behavior" (Nisbett et al., 2001, p. 293). Consequently, due to different styles of thinking, consumers evaluate branding 
activities from different perspectives. Because sport businesses are often conducted at the global level, it is important to examine the effect of cultural differences on consumer's evaluation of branding. However, brand extension and cobranding studies, especially at the cultural level, is surprisingly lacking within the domain of sport.

Cross-cultural studies on cobranding can offer important marketing implications for businesses and sport organizations competing in today's global economy. More specifically, research on how Asians differ from Americans in their comparison of cobranding pairs that involve sport versus non-sport brands can offer important insights for enterprises who target internal consumers. This type of research would offer insights to researchers and practitioners searching for a way to approach consumers from different backgrounds. Given the recent interest of consumer behavior research in the different brand evaluations of diverse cultures (e.g. American market vs. Asian market), it is necessary to investigate if cross-cultural variation exists when consumers engage in the evaluation of cobranded sport merchandise. This need is further justified in four aspects. First, studying consumer's cobrand evaluation within the domain of sport is needed due to lack of research investigation in the existing literature. Second, empirical evidence that supports cobrand evaluation schema when sport merchandise is involved is still lacking. Third, the lack of replication of such an important consumer behavior concept within the sport domain limits generalizability of the findings. Last, researchers have criticized that most of the existing cross-cultural brand evaluation studies have exclusively been conducted toward American consumers (John, 2004; Monga \& John, 2007; Yoon \& GurhanCanli, 2004).

This study investigates whether cross-cultural differences exist when consumers evaluate cobranded athletic merchandise. Cobranding has been recognized as a relatively new business tactic that needs to be better understood as athletic merchandise continues to expand into global markets. Findings from this type of research would enable practitioners and scholars to gain marketing insights with respect to how individuals not only evaluate cobranding 
practices, but also how cultural differences impact brand evaluation among global consumers of athletic team merchandise.

\section{Review of Literature}

Theoretical Justification for Consumer Brand Evaluations in General

Categorization theory and schema congruity theory are the two theoretical bases for brand evaluation studies including the current study. Categorization theory generally indicates that consumers evaluate brand extensions based on perceived similarity (or dissimilarity) of products that are in the same (or different) category. Dawar (1996) found that the strength of association between the brand and the products it represents influences consumer brand extension evaluations. He argued that in addition to the variability, the pattern of associative strengths influences the ability of consumers to retrieve related information for processing, and thus it also influences fit judgments for the brand extension evaluation. This idea is consistent with Mervis and Rosch's (1981) concept of typicality. As products are perceived as more typical members of a category, they are more likely to be evaluated similarly. This high perceived similarity will then be translated as high fit, resulting in more positive brand extension evaluations.

Schema congruity theory is an alternative explanation for the role of "fit" in brand evaluations. Meyers-Levy and Tybout (1989) indicated that consumer's perceived congruity (or incongruity) in product attributes contributes to product evaluations. They pointed out that congruity is a function of matching whereas incongruity is a consequence of mismatch. Other researchers indicated that perceived brand fit is determined based on brand image fit (Bhat \& Reddy, 2001; Park, Jaworski, \& MacInnis, 1986). Fitness (image similarity or congruency) of two brands can be better understood from quality and functionality perspectives as well. James (2005) supported this premise by demonstrating that consumers often evaluate brand (extension) fit in terms of quality as well as functionality.

\section{Theoretical Justification for Cross-Cultural Variation}

Analytic and holistic paradigms have been adopted to understand cross-cultural differences in consumers' brand 
evaluations. More specifically, analytic thinkers, like Americans, often focus on the attributes of a product and the product's similarity to a particular category like 'sport' product in order to make judgments (Monga \& John, 2004). The literature generally indicates that the fitness of brands is judged by consumers in terms of product class similarity and attribute relevancy. For example, Nike's Band designed for sport participants as wearable 'sport' gear may be thought of by future users as a natural addition to Nike's current product classes. This implies that when evaluating a pair of brands consumers consider whether the encountered brands belong to similar product category in regards to the primary brand; additionally, consumers consider whether there is relevancy in product attributes between the encountered brands. Based on this information, consumers are likely to perceive high cobrand "fit" when high attribute relevancy and product category similarity are recognized. In contrast, consumers are likely to perceive low cobrand "fit" when low attribute relevancy and product category dissimilarity are recognized.

Holistic thinkers like Asians, however, tend to focus on relationships between objects and the field, which suggest that they are likely to consider an aspect such as complementarity as a basis of brand fit (Choi, Nisbett, \& Norenzayan, 1999). An example to this premise is that each brand in a cobranding set up complement each other and thus enhances the overall image to consumers. Choi, Nisbett, and Norenzayan further argued that as a result of this cultural variation in perceptions, consumers in the Eastern culture are more likely to judge brand fit more favorably than Westerners (i.e., analytic thinkers). Ji, Peng, and Nisbett (2000) supported this cultural difference in brand fit evaluation processes by indicating that Asians tend to be relationship dependent more than Americans, implying that the fitness of brands can be determined based on the degree of brand relationships in which holistic thinkers pay greater attention.

Based on the review of literature, the current study attempts to answer the following research questions: 1) How do varying aspects (brand image fit, brand functionality fit, brand quality fit) of brand fit impact an individual's purchase intention of cobranded 
products? 2) How does an individual's attitude toward cobranded products generally impact their purchase intention (i.e., cognitive intention to make a purchase)? Comparison of cross-cultural differences between American consumers and Asian consumers were also examined in relation to the two research questions. Attitude was defined as cognitively learned predisposition to respond to a given object (Eagly \& Chaiken, 1993).

\section{Method}

\section{Study Design, Sample, and Procedure}

The objectives of the current exploratory research were achieved in three phases: 1) pilot test I (a testing brand was identified to create cobrands), 2) pilot test II (psychometric properties of the scales measuring items towards the cobrands were examined), and 3) a main study (cross-cultural difference test was performed between Americans and Asians). Using a survey method, two convenience samples for the two pilot tests were collected from students majoring in sport administration and exercise science in a Midwestern university in the United States. From collegiate athletic events including football, basketball, and volleyball games, data were collected from the same university for a larger and more generalizable data in the main study. Using a snow-balling technique (a non-probability sampling also known as referral sampling), separate data consisting only of non-US citizens were collected from the same or similar collegiate athletic events at two other Midwestern universities over the course of three weeks (for the purpose of cross-cultural examination). To access a subpopulation who has been exposed to the same brands as most of Americans, non-US citizens residing in the US were targeted. To minimize the acculturation effect (i.e., 'Americanized') in the cross-cultural sample, non-US citizens who resided in the states less than 3 years were targeted in the current study.

Brief instructions were given to the respondents prior to distributing the questionnaires, and respondents completed a voluntary participation consent form as required by the university's Institutional Review Board. Participants were first shown a predetermined manufacturer brand (i.e., Champion) from the pilot 
study and were asked to indicate their favorite athletic team. The initial pilot testing was to identify a testing brand that is not too favorable but also recognizable to participants (refer to 'Instruments' section for more detail). Only one testing brand was used to minimize the effect of brand recognition variation. Then, the participants were asked to respond to the remaining items based on the pairing of the participant's favorite athletic team and the Champion brand, which created 'cobranding' for each of the participants. Considering Hair, Black, Babin, and Anderson's (2010) suggestion, a minimum of 150 participants were needed for the main study. The majority of the American sample $(n=160)$ consisted of individuals age between 18 and 63 years old $\left(M_{\text {age }}=28.48 ; S D=\right.$ $12.52)$, Caucasian/White $(90.0 \%)$, and male (51.9\%). The majority of the Asian sample $(n=162)$ consisted of individuals age between 18 and 44 years old $\left(M_{\mathrm{age}}=28.47 ; S D=5.25\right)$ and male $(71.0 \%)$. The ethnicity consisted of 142 Koreans, 13 Chinese, and 7 Indians.

\section{Instruments}

In the pilot test I, participants ranked 1 as the most recognizable and the 13 as the least recognizable brand. The Champion brand had the mid-level brand recognition among the thirteen existing brands (e.g. Nike, Reebok, Under Armour, Russell) and thus was chosen as a testing brand in the current study. Using this testing brand, a hypothetical cobrand scenario was created to collect data for the overall items. First, to measure varying aspects of perceived brand fit (PBFIT), Bhat and Reddy's (2001) items were slightly modified and used. More specifically, two items measuring each of the three types of brand fits were included in the instrument. The three types of brand fits were brand extension image fit, brand extension quality fit, and brand extension functionality fit.

Cronbach's alpha for the original items (brand image fit) was 0.75 .

To measure attitude toward cobranding, Laroche, Kim, and

Zhou's (1996) items were slightly modified and used. This construct was measured using three items including favorableness, likeness, and goodness. Cronbach's alpha for the original items was 0.93 or greater. To measure purchase intension of cobranded athletic team products, Hagger, Chatzisarantis, and Biddle's (2001) items were slightly modified and used (e.g. "in the future, I am likely to 
purchase more of (participant's favorite athletic team) merchandise sponsored by Champion brand"). Three items were used to measure this construct. Cronbach's alpha for the original items was 0.77 .

Data for the cross-cultural comparison was collected using the same instrument. All items were measured on a 7-point Likert-type scale in the current study. In the pilot test II of the present study, Cronbach's alpha values were identified as follows: 0.88 (brand image fit), 0.89 (brand quality fit), 0.85 (brand functionality fit), 0.73 (attitude toward cobranding), and 0.95 (purchase intention).

\section{Data Analysis}

To assess reliability and validity of the instruments, a pilot test (i.e., pilot test II) was conducted with a sample of 54 college students enrolled in two sport administration classes at a Midwestern university in the U.S. Using SPSS Version 19.0, Cronbach's alphas were calculated. Prior to the main data analyses to test cross-cultural differences, psychometric properties of the scales were reexamined. To conduct cross-cultural examinations to the extent how Americans and Asians react to cobrandings, two multiple regressions were conducted on purchase intention using both American sample and Asian sample. To minimize the type I error when running two regressions on the same variables, the alpha level was adjusted from .05 to .025 (Hair et al., 2010). Tolerance and variance inflation factor (VIF) were tested to check the multicollinearity.

\section{Results}

\section{Descriptive Statistics and Correlations}

Attitude had the highest mean in both populations while the lowest mean was found in Purchase Intention using the American sample and in Brand Image Fit using Asian sample (refer to Table $3)$. In both samples, the highest correlation was found between Brand Functionality Fit and Brand Quality Fit ( $r=.77$ in American sample and .79 in Asian sample) while the lowest correlation was found between Attitude toward Cobranding and Brand Image Fit ( $r$ $=.57$ in American sample and .42 in Asian sample; refer to Table 1). Psychometric Properties of the Instruments

In both populations, Cronbach's alphas for all variables were above .707, except for Brand Image Fit in the American sample 
(refer to Table 1). Discriminant validity among the overall variables was established in that all correlations were lower than 0.85 (Kline, 2005; refer to Table 1). While the reliability for the brand image fit when using American sample is a concern, the overall findings collectively provided evidences for good psychometric properties of the scale. Overall values for Tolerance and VIF in Table 2 indicate none severity of multicollinearity.

Table 1

Mean, Standard Deviation, Cronbach's Alpha, and Factor Correlation

\begin{tabular}{|c|c|c|c|c|c|c|}
\hline \multirow[t]{2}{*}{ Sample } & \multirow[t]{2}{*}{ Variables } & \multirow[b]{2}{*}{ BIF } & \multirow[b]{2}{*}{$\mathrm{BQF}$} & \multicolumn{3}{|c|}{ AT } \\
\hline & & & & $\mathrm{BFF}$ & $\mathrm{C}$ & PI \\
\hline \multirow[t]{8}{*}{ Americans } & Brand image fit & 1 & & & & \\
\hline & Brand quality fit & 0.73 & 1 & & & \\
\hline & $\begin{array}{l}\text { Brand functionality } \\
\text { fit }\end{array}$ & 0.68 & 0.77 & 1 & & \\
\hline & $\begin{array}{l}\text { Attitude toward } \\
\text { cobranding }\end{array}$ & 0.57 & 0.63 & 0.57 & 1 & \\
\hline & Purchase intention & 0.74 & 0.66 & 0.59 & $\begin{array}{c}0.5 \\
9\end{array}$ & 1 \\
\hline & $\alpha$ & 0.60 & 0.82 & 0.87 & $\begin{array}{c}0.8 \\
8\end{array}$ & $\begin{array}{c}0.9 \\
0\end{array}$ \\
\hline & $M$ & 4.38 & 4.52 & 4.81 & $\begin{array}{c}4.8 \\
7\end{array}$ & 4.2 \\
\hline & $S D$ & 1.27 & 1.35 & 1.17 & $\begin{array}{c}1.1 \\
7\end{array}$ & $\begin{array}{c}1.3 \\
4\end{array}$ \\
\hline \multirow[t]{8}{*}{ Asians } & Brand image fit & 1 & & & & \\
\hline & Brand quality fit & 0.72 & 1 & & & \\
\hline & $\begin{array}{l}\text { Brand functionality } \\
\text { fit }\end{array}$ & 0.76 & 0.79 & 1 & & \\
\hline & $\begin{array}{l}\text { Attitude toward } \\
\text { cobranding }\end{array}$ & 0.42 & 0.57 & 0.55 & 1 & \\
\hline & Purchase intention & 0.65 & 0.70 & 0.75 & $\begin{array}{c}0.5 \\
6\end{array}$ & 1 \\
\hline & $\alpha$ & 0.77 & 0.79 & 0.76 & $\begin{array}{c}0.8 \\
5\end{array}$ & $\begin{array}{c}0.9 \\
2\end{array}$ \\
\hline & $M$ & 2.80 & 2.85 & 2.98 & $\begin{array}{c}3.6 \\
1\end{array}$ & $\begin{array}{c}3.0 \\
8\end{array}$ \\
\hline & $S D$ & 1.38 & 1.25 & 1.34 & $\begin{array}{c}1.2 \\
9\end{array}$ & $\begin{array}{c}1.3 \\
7\end{array}$ \\
\hline
\end{tabular}




\section{Regression Analysis}

When the four independent variables were regressed on American's purchase intention of cobranded products, three variables had statistical significance at the .025 (alpha adjusted) alpha level. The three variables were Brand Image Fit, Brand Quality Fit, and Attitude toward Cobranded Products, explaining approximately $53 \%$ of the variance. At the univariate level, their coefficients were $.288, .243$, and .220 , respectively, indicating all positive influence on the purchase intention (refer to Table 2).

When a separate regression was applied toward Asian's purchase intention of cobranded products, somewhat different results were obtained. Brand Quality Fit, Brand Functionality Fit, and Attitude variables had statistical significance, explaining approximately $62 \%$ of the variance. At the univariate level, their coefficients were $.207, .385$, and .176 , respectively, indicating all positive influence on the purchase intention (refer to Table 3 ).

Table 2

Multiple Regression Results towards Americans $(N=160)$

\begin{tabular}{|c|c|c|c|c|c|}
\hline \multirow[t]{2}{*}{$\begin{array}{c}\text { Independent } \\
\text { Variables }\end{array}$} & $\begin{array}{c}\text { Standardized } \\
\text { Coefficients }\end{array}$ & \multirow[t]{2}{*}{$t$} & \multirow[t]{2}{*}{ Sig } & \multicolumn{2}{|c|}{$\begin{array}{l}\text { Collinearity } \\
\text { Statistics }\end{array}$} \\
\hline & Beta & & & $\begin{array}{c}\text { Tolera } \\
\text {-nce }\end{array}$ & VIF \\
\hline Image Fit* & .288 & $\begin{array}{l}3.2 \\
22\end{array}$ & $\begin{array}{c}.00 \\
2\end{array}$ & .419 & 2.389 \\
\hline Quality Fit* & .243 & $\begin{array}{l}2.3 \\
25\end{array}$ & $\begin{array}{c}.02 \\
2\end{array}$ & .306 & 3.266 \\
\hline $\begin{array}{l}\text { Functionality } \\
\text { Fit }\end{array}$ & .087 & $\begin{array}{c}92 \\
7\end{array}$ & $\begin{array}{c}.35 \\
6\end{array}$ & .378 & 2.646 \\
\hline Attitude* & .220 & $\begin{array}{c}2.8 \\
61\end{array}$ & $\begin{array}{c}.00 \\
5\end{array}$ & .565 & 1.771 \\
\hline
\end{tabular}

Note. Dependent Variable: Purchase intention; $\mathrm{R}^{2}=.529 ;{ }^{*}$ indicates statistical significance at the .025 level (alpha adjusted). 
Table 3

Multiple Regression Results towards Asians $(N=162)$

\begin{tabular}{|c|c|c|c|c|c|}
\hline \multirow[t]{2}{*}{$\begin{array}{l}\text { Independent } \\
\text { Variables }\end{array}$} & \multirow{2}{*}{$\begin{array}{c}\text { Standardized } \\
\text { Coefficients } \\
\text { Beta }\end{array}$} & \multirow[t]{2}{*}{$t$} & \multirow[t]{2}{*}{ Sig } & \multicolumn{2}{|c|}{$\begin{array}{c}\text { Collinearity } \\
\text { Statistics }\end{array}$} \\
\hline & & & & $\begin{array}{c}\text { Tolera } \\
\text {-nce }\end{array}$ & VIF \\
\hline Image Fit & .132 & $\begin{array}{l}1.6 \\
61\end{array}$ & $\begin{array}{c}.09 \\
9\end{array}$ & .386 & 2.590 \\
\hline Quality Fit* & .207 & $\begin{array}{l}2.3 \\
63\end{array}$ & $\begin{array}{c}.01 \\
9\end{array}$ & .320 & 3.122 \\
\hline $\begin{array}{l}\text { Functionality } \\
\text { Fit* }\end{array}$ & .385 & $\begin{array}{l}4.1 \\
64\end{array}$ & $\begin{array}{c}.00 \\
0\end{array}$ & .286 & 3.491 \\
\hline Attitude* & .176 & $\begin{array}{c}2.8 \\
65\end{array}$ & $\begin{array}{c}.00 \\
5\end{array}$ & .647 & 1.546 \\
\hline
\end{tabular}

Note. Dependent Variable: Purchase intention; $\mathrm{R}^{2}=.616 ; *$ indicates statistical significance at the .025 level (alpha adjusted).

\section{Discussion}

\section{Key Findings and Comparison to the Literature}

The current study examined the evaluation of cobranding in sports by cross-cultural consumers (i.e. Americans and Asians). Two research questions guided the current study. The first research question examined how varying aspects (brand image fit, brand functionality fit, brand quality fit) of brand fit evaluation impacted individual's purchase intention of cobranded products and if there was any cross-cultural difference. The second research question examined how individuals' attitude toward cobranded products impacted their purchase intention and if there was any cross-cultural difference. The overall findings indicated that image fit evaluation was an important consideration for American consumers' purchase intention of cobranded athletic merchandise, but it was not important for the Asian consumers. However, functionality fit was an important consideration for Asian consumers' purchase intention of cobranded athletic merchandise, but it was not important for the American consumers. These findings offer generally contrary ideas to the existing literature. For example, the literature has generally indicated that the results should have been the opposite of what was found in the current study. However, there is no complete consensus in the literature. 
There are four potential explanations why the results of this study differ from conclusions drawn in prior research. First, the current study utilized athletic merchandise and sport brands as opposed to non-sport brands typically studied in other disciplines. For example, Monga and John's (2007) brand fit evaluation study was conducted by utilizing a few hypothetical brand extensions within general consumer good category that included Kodak shoes, McDonald razor, and Mercedes-Benz watch. Unfortunately, the sport literature is devoid of any studies that have investigated consumer evaluation of athletic merchandise brands from a crosscultural perspective. As a result of these contradictory findings, there needs to be further research to generalize the consumer perspectives in cobrand evaluations of athletic merchandise. Although the athletic merchandise plays an important role in the overall sport industry, few empirical findings have offered generalizable insights to suggest implications for practitioners and researchers in the field of sport particularly in the context of cobranding (Lee, Kroncke, and Johnson, 2012).

The second factor that may explain these results is that there is a difference between examining brand extension and co-branding situations. Monga and John (2004) indicated that Americans are likely to be analytic thinkers and thus tend to focus on product attributes when evaluating brand fit. Because product attributes such as dry fit, comfortness of fabric, and/or unique color schemes are key ingredients for functionality fit evaluation in athletic brands, these elements of functionality fit should be more important for Americans than Asians when evaluating brand fit. It is worth noting that previous studies were conducted under the premise of brand extension evaluations not cobranding situations. As defined by Aaker and Keller (1990), brand extension strategies focus on the effective utilization of existing brand equity to produce a new product in a different product category, while the focus of cobranding is on the practice of brand alliance (Walchli, 2007).

Third, the sport literature has examined brand extension in the context of a team, but not in the context of athletic apparel and manufacturing. Among the few existing studies was Walsh, Chien, and Ross' (2012) team brand extension research. They indicated that 
brand extension strategies have become very common in sport, but relatively little research has been conducted in this area. They examined image fit between Taiwanese pro-baseball teams as brand extensions and their parent corporate brands, illustrating there was no strong role of fit evaluation in the overall image of corporate brands. Rather, it was found that team success had a more salient impact on the consumer's overall perception than the evaluation of image fit. Additionally, Richelieu, Lopez, and Desbordes (2008) proposed that one of the key successes of branding efforts by European soccer teams was the consumer perception of the internationalization of club operations. Their model conceptualized various stages of branding strategy that sports clubs could implement in relation to the positioning status at the level of local, regional, national and international.

Fourth, past studies have utilized analysis of variance tests to determine group differences, but this study utilized regression analysis. Monga and John (2007), for example, conducted analysis of variances to see if American consumers and Indian consumers would be different in their overall ratings of brand fit (i.e., Kodak shoes and McDonald razor). They found conflicting results in consumers' evaluation of brand fit. More specifically, they found that when prestigious brands were tested (i.e., Mercedes-Benz watch), there was no significant group difference in overall evaluation of brand fit between Americans and Indians. In contrast, they found significant group differences when less prestigious brands were tested as described above. They concluded that the significant difference in consumer brand extension evaluation between consumers in two global markets seemed to be affected by differing styles of thinking. It is worth noting that particularly from a predictive standpoint, the current sport literature lacks empirical support to generalize consumer evaluation of athletic brands because many sport and non-sport studies have looked at cross-cultural group differences by comparing mean scores (i.e., t-test, ANOVA). We believe regression has not been used in previous studies to predict consumers' connotative behavior in regards to cobranded athletic merchandise. Regression analyses were used in the current study to predict respondents' intention to purchase hypothetically generated 
cobranded athletic products. Up to $62 \%$ of variance was explained by the chosen brand fit measures.

It is worth note that this research highlights the need for cross-cultural research on branding especially within the realm of athletic merchandise. In sum, the current study offers insights to the consumer evaluation of cobranded athletic merchandise at the crosscultural level. This type of research needs to be continued at the cross-cultural level, especially in developing countries where more business opportunities await.

\section{Limitations and Recommendations}

Several limitations were identified, and recommendations were made for future research. Use of one sample from each culture may not be sufficient to represent each culture. The Asian sample was heavily populated with Koreans and thus the cross-cultural results were not generalizable onto the broader Asian culture. In order to increase generalizability, using multiple samples from various cultures and comparing the overall findings will be ideal. In addition, data collection using different athletic brands, preferably athletic brands with different levels of brand recognition (e.g. Nike, New Balance, Russell, and Champion) will increase generalizability. The literature generally indicates that brand evaluation "differences are robust for extensions that range from very low to moderate fits with the parent brand" (Monga \& John, 2007, p. 535). By the same token, testing consumer evaluation of cobranding with varying levels of fit will likely make a greater contribution to the sport literature. Future research should thus incorporate globally recognized brand as well as moderately (or poorly) recognized athletic brands in the same study. 


\section{References}

Aaker, D. A., \& Keller, K. L. (1990). Consumer evaluations of brand extensions. Journal of Marketing, 54, 27-41.

Bhat, S., \& Reddy, S. K. (2001). The impact of parent brand attribute associations and affect on brand extension evaluation. Journal of Business Research, 53, 111-122.

Campbell, R. M. Jr., \& Kent, A. (2002). Brand extension evaluation: The case of NFL Europe. Sport Marketing Quarterly, 11(2), 117-120.

Choi, I., Nisbett, R. E., \& Norenzayan, A. (1999). Causal attribution across cultures: Variation and universality. Psychological Bulletin, 125(1), 47-63.

Dawar, N. (1996). Extensions of broad brands: The role of retrieval in evaluations of fit. Journal of Consumer Psychology, 5(2), 189-207.

Eagly, A., \& Chaiken, S. (1993). The psychology of attitudes. Fort Worth: Harcourt Brace Jovanovich College.

Estimated retail sales in U.S. and Canada. (2007, August 13). Street \& Smith's Sports Business Journal, p. 19.

Hagger, M. S., Chatzisarantis, N., \& Biddle, S. J. H. (2001). The influence of self-efficacy and past behavior on the physical activity intentions of young people. Journal of Sports Sciences, 19, 711-725.

Hair, J. F., Black, W. C., Babin, B. J., Anderson, R. E. (2010). Multivariate data analysis (7th ed.). Upper Saddle River, NJ: Prentice Hall.

Hillyer, C., \& Tikoo, S. (1995). Effect of cobranding on consumer product evaluations. Advances in Consumer Research, 22, 123-127.

James, D. (2005). Guilty through association: Brand association transfer to brand alliances. Journal of Consumer Marketing, 22(1), 14-24.

Ji, L-J., Peng, K., \& Nisbett, R. E. (2000). Culture, Control, and Perception of Relationships in the Environment. Journal of Personality, and Social Psychology, 78(5), 943-955. 
Keller, K. L., \& Aaker, D. A. (1992). The effects of sequential introduction of brand extensions. Journal of Marketing Research, 26, 35-50.

Kim, C., \& Heere, B. (2012). Consumers from emerging markets: Perceptions and attitudes toward global sporting brands. Sport Marketing Quarterly, 21, 19-31.

Kline, R. B. (2005). Principles and Practice of Structural Equation Modeling. New York: The Guilford Press.

Laroche, M., Kim C., \& Zhou, L. (1996). Brand familiarity and confidence as determinants of purchase intention: An empirical test in a multiple brand context. Journal of Business Research, 37, 115-120.

Lee, D., Kroncke, C., \& Johnson, J, E. (2012). Consumer evaluation of brand fit, attitude, and purchase intention of athletic team merchandise. International Journal of Sport Management and Marketing, 11(3/4), 158-171.

Levin, A. M. (2002). Contrast and assimilation processes in consumers' evaluations of dual brands. Journal of Business and Psychology, 17(1), 145-154.

Loken, B., \& Roedder, J. D. (1993). Diluting brand beliefs: When do brand extensions have a negative impact? Journal of Marketing, 57, 71-84.

Mervis, C. B., \& Rosch, E. (1981). Categorization of natural objects. Annual Review of Psychology, 32, 89-115.

Meyers-Levy, J., \& Tybout, A. M. (1989). Schema congruity as a basis for product evaluation. Journal of Consumer Research, $16,39-54$.

Monga, A. B., \& John, D. R. (2007). Cultural differences in brand extension evaluation: The influence of analytic versus holistic thinking. Journal of Consumer Research, 33, 529536.

Monga, A. B., \& John, D. R. (2004). Consumer response to brand extensions: Does culture matter? Advances in Consumer Research, 31, 216-222.

Nisbett, R. E., Peng, K., Choi, I., \& Norenzayan, A. (2001). Culture and systems of thought: Holistic versus analytic cognition. Psychological Review, 108, 291-310. 
Park, C. W., Jaworski, B. J., \& MacInnis, D. J. (1986). Strategic brand concept-image management. Journal of Marketing, 50, $135-145$.

Richelieu, A., Lopez, S., \& Desbordes, M. (2008). The internationalization of a sports team trend: The case of European soccer teams. International Journal of Sports Marketing \& Sponsorship, 10(1), 29-44.

Roedder, J. D., Loken, B., \& Joiner, C. (1998). The negative impact of extensions: Can flagship products be diluted? Journal of Marketing, 62, 19-32.

Walchli, S. B. (2007). The effects of between-partner congruity on consumer evaluation of co-branded products. Psychology \& Marketing, 24(11), 947-973.

Walsh, P., Chien, C-I. J., \& Ross, S. D. (2012). Sport teams as brand extensions: A case of Taiwanese baseball. Sport Marketing Quarterly, 21, 138-146.

Yoon, Y., \& Gurhan-Canli, Z. (Eds.). (2004). Cross-cultural differences in brand extension evaluations: The effect of holistic and analytical processing. Advances in Consumer Research, 31, 2 
The Journal of SPORT, 2014, 3(2), 221-245

(C) Kent State University

\title{
You Have the Right to Tweet, But It Will Be Used Against You: Balancing Monitoring and Privacy for Student-Athletes
}

\author{
Lauren McCoy \\ Western Kentucky University
}

\begin{abstract}
In recent years, social networking has taken on new levels of importance in our society. The impact of social networking has had a major effect on sport media because these sites allow 24/7 contact with athletes for fans and media. While there are many advantages to social media, this constant contact could lead to public relations issues for sports organization, in particular, for universities whose student-athletes may not realize the impact of their words on social media. The first instinct of many is to monitor the information being released via social media by their athletes, but the growing legal climate towards privacy elicits the need to monitor with caution. The purpose of this article is to examine university social media policies and regulation trends as they relate to new privacy regulations that limit the boundaries of monitoring in connection to student-athletes.
\end{abstract}


Interest in social media platforms continues to grow as the instant availability of the Internet expands beyond our homes and computers. Facebook and Twitter, two of the most popular social media platforms, are actively used by 1.23 billion and 241 million users respectively. Active usage is defined by users logging into the social media site at least once a month (Sherman, 2014). These social networking sites allow people to stay in touch, whether they're in the house next door or in another country, and have had a profound effect on the way media, both news and sport, is covered in the U.S. The instantaneous nature of social networking allows news stories to be published both nationally and internationally with the click of a single button. This inundation of information available through social networking sites has created a new form of media that has widespread use in sport: social media. Further, these sites provide $24 / 7$ access to athletes for the media and fans of the team/organization.

While there are many benefits to social networking sites, recent controversies, as told through social media, illicit the need for caution. In May of 2013, a football player at Columbia University in New York was charged with a hate crime after allegedly threatening and taunting another student with racial slurs (Patterson, 2013). This arrest exposed a series of racially insensitive and sexually explicit tweets between the accused and other members of the Columbia University Football team. A collection of 46 posts made on Twitter (also known as tweets) established a record of anti-gay and racially motivated statements made over a series of weeks by members of the football team (Schwab, 2013). This type of news provides embarrassment to any organization, especially an educational institution where we hope to encourage diversity and acceptance. The embarrassment caused by events like these is only compounded by the instant accessibility to private thoughts and conversations through social media. Unfortunately, these types of social networking related controversies are not uncommon. Anyone associated with sport, whether he or she is a professional athlete, 
coach, or student-athlete is in danger of social media commentary affecting their personal and professional futures.

Social media platforms are particularly dangerous for student-athletes, as the above example shows. While these studentathletes are often very well-known by those that follow their particular sport, they are often blind to the need for caution and choosing your words carefully as a celebrity. The communications that led to arrest and other troubles for those Columbia University athletes were likely meant to be private communication among friends. However, the public nature of social networking does not often allow for privacy, a concept that many social networking users often fail to grasp. When student-athletes use social networking sites, their main purpose is to stay in contact with friends and family, communicate with followers and to access information (Browning \& Sanderson, 2012). That primary focus on personal communication can make it difficult for those who have achieved online celebrity status to visualize the line between public and private communication.

The public visibility of social media combined with the desire to communicate with friends and family has led to decisions that affect the professional future of many, particularly for studentathletes. In an attempt to avoid negative press, schools and universities have begun to monitor the social media activity of student-athletes to weed out what they deem to be inappropriate behavior. These policies tend to be stricter in terms of monitoring and the resulting consequences for student-athletes (Sanderson, 2011). In 2012, the University of Michigan stopped recruiting cornerback Yuri Wright due to the derogatory comments he made on Twitter. Wright was also expelled from his high school for these comments (Staples, 2012). The devastating consequences associated with social media monitoring for student-athletes has led to the development of new laws meant to protect student-athletes' social media privacy.

As our use of the internet expands, so too has legislation to protect the privacy rights of internet users. Social media privacy 
rights were first targeted towards employees who were being asked by employers for their social media user names and passwords to monitor the content (House Bill 964, 2012). Employees were typically consenting to this social media access for fear of negative employment impacts. While it does take time, the law eventually catches up to technology. Social media is not inherently private, but those using social media platforms deserve a modified sense of privacy adapted to this new technology (Poore, 2013).

The continued growth of social media aggravates the perceived danger associated with these sites by those in power, leading to monitoring and appropriate punishments for misdeeds. But this monitoring cannot be done without thinking of the legal ramifications. Social networking accounts, especially those not made publicly available, are entitled to some form of privacy under the law in many states. Most recently, this social media legislation has focused on the privacy rights of students and a successful college program must be wary of the legal ramifications of monitoring student-athlete social networking usage. While the majority of student-athletes may not be concerned with what their coach or their school sees on their Facebook or Twitter accounts, they may be entitled to certain levels of privacy under the law and a school will have limited arguments if their monitoring policies are ever challenged in court.

The purpose of this article is to highlight the impact of privacy law on existing social media monitoring trends. These trends establish a sample to understand how colleges are monitoring student-athlete online content. Comparing these trends with the parameters of existing law provides a hypothetical response should a student-athlete ever challenge their university's social media policies. This article focuses on student-athletes due to the harsh punishments given to student-athletes for social media miscues versus the response given to an employee. While an employee may lose their job for comments posted on social media, a student-athlete could lose their scholarship along with their ability to play college sports for any NCAA institution. Additionally, because university 
social media policies are directly primarily towards the studentathlete, the better legal comparison involves those policies meant to protected the rights of students.

This article will identify the current trends for monitoring student-athlete social networking activity including the common practice methods used by universities. Next, this article will highlight the history of privacy law and social media legislation as it affects students. This examination into privacy law will focus on the wordings of each law and will propose a potential interpretation based on the elements of the law to determine the legal viability of each monitoring trend. Understanding what is banned under current law and where these laws currently exist allows universities to create better strategies for monitoring; and comparing existing social media policy within the current structure of the law will provide universities a model to regulate effectively within the parameters of the law.

\section{Trends in Social Networking Monitoring and Regulation}

Social media monitoring exists at both the professional and educational areas of American society. These monitoring efforts are increasing rapidly in educational institutions because social networking usage is highest among those between 18 and 29 (Brenner \& Smith, 2013). According to a late 2012 study conducted by Pew Research Center, young adults are more likely to use social networking that any other age demographic. $83 \%$ of $18-29$ year olds surveyed use social networking sites. Facebook, Twitter and Instagram are the most popular sites among that demographic (Duggan \& Brenner, 2012). Due to this increased usage by young adults, it is not surprising that student-athlete usage of social networking continues to grow. A Fieldhouse Media survey on social media use by student-athletes conducted in 2012 found that $72 \%$ of athletes surveyed have a Twitter account with $97.4 \%$ using the site daily, $93.5 \%$ have a Facebook account, and $64.81 \%$ have an Instagram account (DeShazo, 2013). 
Social networking monitoring programs were established to assist efforts to protect schools and other organizations from damaging information released online. When a student-athlete provides harmful information via social media, negative implications are possible for both the athlete and his institution. The University of North Carolina - Chapel Hill (UNC) became a cautionary tale for those concerned with social networking after the NCAA's Committee on Infractions released the following statement in their report.

"During 2009 and 2010, the institution failed to monitor the conduct and administration of the football program. Specifically, the institution failed to a) monitor the activities of former student-athlete $\mathrm{A}$; and $\mathrm{b}$ ) investigate information it obtained suggesting that studentathlete 5 may have been in violation of NCAA legislation." (Infractions, 2012)

Student-athlete 5 is widely assumed to be Marvin Austin, a former defensive back for UNC. On May 29, 2010 Austin sent out this tweet: "I live in club LIV so I get the tenant rate. bottles comin [sic] like its [sic] a giveaway." His words were referencing a song from rap artist, Rick Ross; however, this simple tweet led to an investigation by the NCAA and media sources regarding the possibility of any impermissible benefits. The NCAA eventually uncovered a series of potential violations due to improper benefits based on information provided via Austin's Twitter account containing 2,400 other tweets at the time (Giglio, 2010). While the information found through social media was only a small portion of the violations present at UNC, the NCAA's Committee on Infraction's report cautioned other universities to be wary of studentathlete social media use.

This paragraph signaled that a University has some responsibility to monitor the social media activity of its studentathletes. If $\mathrm{UNC}$ had monitored in this instance, these violations may have been uncovered early enough to allow for self-reporting and/or lesser penalties. UNC took this warning seriously by establishing 
social media policies for student-athletes and the football team later football student-athletes from using Twitter.

As a result of the issues caused by social media for UNC and other institutions, many universities have established social media policies to protect the reputation of both the student-athlete and the university. These monitoring policies are often in attempt to maintain institutional control (Hopkins, Hopkins, \& Whelton, 2013). In a 2011 study, Jimmy Sanderson examined the social media policies at Division I institutions. At the time, 159 institutions had social media policies in their student-athlete handbook and these social media specific policies were between 33 and 1,037 words in length (Sanderson, 2011). There are larger social media policies at universities that affect faculty and staff; however, the policies found within student-athlete handbooks can be used to punish and contain the monitoring language that may conflict with established privacy law. These policies typically contained language designed to protect the student-athlete by prohibiting certain content and warning student-athletes of online dangers including predators looking to expose bad behavior (Sanderson, 2011). This emphasis on prohibited conduct instead of education has a secondary effect of creating the need for monitoring.

While the social media policies typically alert the studentathlete about the dangers of social media, the warnings issued concerning inappropriate behavior tend to be vague. Taking a broad approach to defining inappropriate content on social media allows for universities to monitor all social media communications. This strategy allows, teams, and by extension, athletic departments and universities have a long reach to punish any content deemed to be detrimental and even remove potential offending content. Monitoring can be done in-house by coaches, other athletic staff, or conducted by third-party companies that specialize in monitoring. 16 of the 159 policies examined by Sanderson specifically required student-athletes to send friend requests to coaches or athletic department personnel in charge of monitoring (Sanderson, 2011). 
The lack of specific definition for inappropriate content may allow for expanded monitoring efforts but it also makes it difficult for student-athletes to recognize what they should and should not say in a public forum like Twitter. A surprising number of studentathletes have admitted to posting something inappropriate on these websites. The 2012 Fieldhouse Media survey defined inappropriate material as anything racial, sexual, violent, profane, or in support of drug/alcohol use. Of those surveyed, $23.1 \%$ of student-athletes admitted to posting something inappropriate on Twitter in comparison to the $22.3 \%$ on Facebook and $14.3 \%$ on Instagram (DeShazo, 2013). While this survey is only a small sampling of student-athletes using social media, it would not be difficult to predict similar usage among the entire group. Around $20 \%$ does not equal a large problem in terms of inappropriate material, but remember; this survey only calculated what those student-athletes perceived to be inappropriate. Without proper education or monitoring of social media activity of student-athletes, the problem could grow exponentially and create issues for the athlete and the institution they represent.

There are three main methods for regulating social media usage typically employed by athletic departments: bans, guidelines without monitoring and policies that include monitoring. Bans are effective because they completely limit student-athlete access to these sites. A ban also protects a student-athlete from scrutiny by the media or fans/rivals. Typically, athletes do not complain about these bans because playing sports is more important to them than social networking. T.J. Yates, former UNC quarterback, once famously tweeted " $[\mathrm{t}] \mathrm{o}$ Tweet or play football???? That's an easy decision.... Bye Bye twitter I am really gonna miss you guys....see you in about 3 months" after a Twitter ban was imposed for UNC football (Walsh, 2010). However, not all student-athletes are committing violations or are using social networking to post inappropriate information. These sites do come with a lot of positives, like free publicity for an organization. Further, blanket bans can lead to a 
charge of limiting free speech and privacy as discussed in section II of this article.

Social networking guidelines are about education. These guidelines educate students on how to properly act and respond on social networking sites. Research in this area was limited to Division I guidelines and policies available online for public access. Of those guidelines found, several common themes emerged. Guidelines typically warn student-athletes of the dangers associated with social media, urging them to use caution and to think before they tweet. They're also warned against posting any personal information that could be used against them, including information that could be used by scam artists or embarrassing information that you wouldn't want to be made public. Some guidelines even go as far as warning student-athletes about how their actions online can affect the university (Sanderson, 2011). Several of the guidelines sampled for this article discussed protecting copyrighted works by not posting videos or pictures without permission (Maryland Athletics, 2011). Additionally, one policy even warned about potential NCAA violations that could occur if a student-athlete posted a comment about a recruit on social networking. Guidelines are not entirely effective because they are informative but lack any regulatory abilities. If students are able to pinpoint that their activities are inappropriate, yet still post the information on social networking, this signifies that guidelines alone will be largely ineffective.

The most effective, and unfortunately, least used method of social media regulation is to have a policy that includes monitoring of social media accounts by either a coach, administrator or third party organization. While monitoring has become quite common, it often does not come with social media training on what is appropriate behavior. As noted by Sanderson, social media guidelines and policies warn of bad behavior but rarely discuss the effective methods for using these sites (Sanderson, 2011). Social media policies are similar to guidelines in that they both provide limitations to behavior on social networking. Policies, however, typically also come as a binding contract between the university and 
the student-athlete. The contract connected to these social media policies often highlights that student-athletes can be punished for inappropriate conduct considered detrimental to the team, the school or the NCAA. To punish for inappropriate conduct and material, monitoring is needed. However, this type of monitoring is not likely to eliminate the problem but instead create tension and concern that could lead to more stringent monitoring.

A September 2012 survey conducted by the College Sports Information Directors of America (CoSIDA) highlighted how athletic departments were educating student-athletes on social media use and what monitoring procedures are in place. $55.3 \%$ of those who responded to the CoSIDA survey or 224 schools do monitor student-athlete activity on social media. Monitoring is usually done by members of the athletic department, whether it is the sports information director, a compliance officer or a team coach. Most monitoring is handled manually as only $3.8 \%$ (17 schools) said that they used monitoring software to follow student-athletes.

Interestingly enough, while schools are willing to monitor and punish students for their activity on social media, few schools are using their resources to educate the students beyond the required guidelines or policies. $56 \%$ of the responding schools (over 450 responded to the survey) did not offer any social media training to their students (College Sports Information Directors of America, 2013).

The results of this CoSIDA survey highlight that the current emphasis regarding social media regulation is on monitoring. Simply monitoring the actions of student-athletes online does not remove the threat of improper conduct being linked to the university. Instead, schools have begun to monitor and remove content from social media sites along with punishment if a social media policy is in place. Over $50 \%$ of the schools removed a social media post from a coach or a student-athlete during the last 12 months, according to the CoSIDA survey. $11 \%$ did it more than 10 times during the same time period (College Sports Information Directors of America, 2013).

The active removal of information on social media along with any 
potential punishment based on information posted could lead to conflict with an individual's privacy rights. To effectively monitor social media, athletic departments must be wary of current privacy laws and the associated trends. If social media monitoring is not done in a legal manner, then those departments have only sidestepped one problem to walk into another.

\section{Privacy Law and Social Media Regulation}

The need for privacy laws is indirectly connected to the growth of journalism. One of the earliest calls for privacy law arose from a lawsuit in the mid-1800s. In England, Prince Albert sued defendant Strange to prevent the publication of a series of etchings drawn for the sake of amusement by Prince Albert and Queen Victoria that were meant to be kept private. These etchings were kept in the Queen's private apartment and were reportedly locked away before they were in defendant Strange's possession. The court concluded that the property in question was entitled to some form of privacy because of its personal nature (Prince Albert v. Strange). While this is a decision from the English high court, which has no bearing on law in the United States, this case was discussed at length in a law review article written by Louis Brandeis and Samuel Warren that is considered by many to be the first declaration of the right to privacy in the U.S.

Within the article, Brandeis and Warren discussed how new inventions (the photograph in particular) must also lead to new law to protect the privacy of an individual and the "right to be let alone." This right, however, is not all encompassing. Material that is of a public interest still has the right to be published. Further, this right also does not prohibit the disclosure of material that was first published by the individual claiming a privacy right. Brandeis and Warren understood the need for news, but believed that information that is meant to be private shall be allowed to remain so. Like any law, the right of privacy requires discussion and interpretation to fulfill the required protections. Our interest in others is a common thread in our society, but we must make sure that that desire for 
information continues to protect the privacy of others and be mindful of how new technology could potentially invade the "right to be let alone." (Warren \& Brandeis, 1891)

As technology and society progresses, so to must the law of privacy. If we followed a literal interpretation of the law as presented by Brandeis and Warren, then all social media would be considered unprotected material. They advocated for the protection of privacy to cease once materials were published. Posting online, even if it is only seen by a small group of people, would lead to no protection. The law has instead begun to adapt to allow for protection of these websites even though publication is at the heart of social media simply because it is possible to limit the accessibility of these accounts. If the information is shared with certain individuals, it should be given the same right of privacy that would be granted if it were a private letter between individuals. Typically, the First and Fourth Amendment of the United States Constitution have also been used to protect speech and privacy on a federal level. This article, however, focuses on state legislation instead because of its applicability to both public and private institutions.

When social media first became popular, many saw its usefulness as a means to gain information about other people. That could be something as simple as "facebook stalking," a slang term used to describe using social media to find out information about someone you may or may not know. Or it can be used for more informative purposes, like as a source of material during a background check accompanying a job application/interview process. A study from 2012 noted that two in five employers use social media to screen potential candidates for positions (Kwoh, 2012). These employers are using social media to investigate employees in a similar manner to the way it is applied in college athletics: to screen for any inappropriate posts, pictures or videos that could be detrimental to the individual and the organization.

In the spirit of protecting privacy, many state legislatures have adopted laws limiting employer access to social media accounts. Maryland was the first state to pass this type of legislation 
and sign it into law in May of 2012. The purpose of this legislation was to prevent employers from requesting the social media user names and passwords of employees and potential employees as a condition of employment (House Bill 964, 2012). The legislature focused on the idea that a person should not have to endure a loss of privacy just to retain employment, which revolves back to Brandeis and Warren's central thesis of the "right to be let alone." (Warren \& Brandeis, 1891)

Because employers are not the only group using social media to gain information, similar legislation is now being targeted towards educational institutions. As of May 2014, there are 10 states with some form of social media privacy law for educational institutions: Arkansas, California, Delaware, Illinois, Michigan, New Jersey, New Mexico, Oregon, Utah, and Wisconsin (National Conference of State Legislatures, 2014). Delaware was the first state to enact a law prohibiting excessive social media monitoring by post-secondary institutions. This law prohibits the request or requirement that any student or prospective student disclose their social media password or any other personal information to gain access to their accounts. Schools are also prohibited from asking students to log into their social media sites in the presence of an agent of the institution for the purposes of monitoring. They cannot add tracking software to a student's device nor can they request or require that a student add a representative of the institution to their social media network. Finally, Delaware law prohibits accessing a student's social media site indirectly through a third party who is connected to the student via social media (House Bill 309, 2012).

Using Delaware's social media access legislation as an example, legislatures seem to take issue with monitoring only when that monitoring capability directly forces action from the student or employee. The greater focus of this legislation appears to be the desire to protect communication made from personal and private devices. By prohibiting certain actions only and not establishing a blanket ban on monitoring, the Delaware law seemingly justifies an organization or athletic department's desire to be aware of an 
affiliated employee or student's social media activity but limits the reach of their monitoring capabilities.

The remaining existing social media legislation also focuses on themes reminiscent of Brandeis and Warren by protecting the right of the individual to be let alone. Each existing law, like Delaware, prohibits the request or requirement of passwords or other personal information, like their username along with requiring accessing these sites in the presence of an employee of the postsecondary institution. There are some differences between states as well. Some states explicitly state that these laws do not prohibit the finding of information that is publicly available (Senate Bill 422, 2013). Since the laws vary by state, the best practice of an administrator in charge of social media monitoring is to determine how the law applies in your state. Even if your state currently doesn't have this type of legislation, there is a growing trend towards social media privacy and diligence is the best way to protect yourself and your organization.

What do these laws mean for the athletic department attempting to monitor social media for the protection of their athletes and their universities?

\section{How Does Privacy Legislation Affect An Organization's Response to Social Media Usage by Student-Athletes?}

The main concern for athletic departments and teams seeking to monitor social media activities conducted by their student-athletes should be whether the type of regulation used is legal. No studentathlete has filed a lawsuit to protect their social media privacy; however, the potential success of those arguments has forced others in similar situations to settle.

Recently, the Minnewaska Area school district in Minnesota paid seventy thousand dollars to a former sixth grade student who was punished over disparaging remarks she made on Facebook from her home computer. When school officials received a complaint about this online behavior, the student, Riley Stratton, was forced to give officials her Facebook password or face detention. Fearing 
punishment, she relented, but her family with the help of the American Civil Liberties Union, later sued the school district claiming a violation of free speech and privacy (Benitez, 2014). While this case was ultimately settled, it does establish the viability of social media privacy cases. It is worth noting that social media legislation for student has been introduced by the Minnesota legislature before this case was settled. Minnesota also does not have active legislation controlling employer access to social media usernames and passwords (National Conference of State Legislatures, 2014). This is worth noting because the lack of specific legislation denying access to social media usernames and passwords will not preclude a viable invasion of privacy and violation of free speech lawsuit.

Focusing on the legality of the department's actions will help to avoid any problems in the future if a student-athlete should file a lawsuit in connection to their social media activities. For those athletic departments and teams in states who have yet to pass social media legislation connected to schools, there may be some hesitation to change tactics to comply with laws not yet in existence. However, change is coming. Within three years, 10 states discussed social media privacy for educational institutions and that were later signed into law. This does not include the multitude of states that continue to debate adding this type of legislation (National Conference of State Legislatures, 2014). Additionally, social media controversies involving student-athletes continue to grow, which should be a cause for concern in terms of monitoring and maintaining privacy. Athletic departments and teams do not need to cease all managing responses when it comes to student-athlete use of social media in the wake of changing legislation. Even with the prevailing culture towards enhancing privacy, social media monitoring is legal, but certain parameters must be followed to stay on the right side of the law.

As discussed in section I, there are three current trends for how athletic departments and teams handle the use of social media by student-athletes. Since each of these trends create different results 
in terms of monitoring and privacy regulation, social media legislation will affect the trends in different fashions.

First, social media bans call for a blanket prohibition against social networking sites by student-athletes. These blanket bans stop all social networking usage and thus limit the need for monitoring. Because no monitoring is attached, any organization utilizing a social media ban does not need to be concerned about educational institution access to social media legislation. These bans could potentially run afoul of the law in another way due to First Amendment right to free speech concerns; however, the documents voluntarily signed by student-athletes prior to participation minimize any potential First Amendment claim (Penrose, 2013). While this article focuses on privacy legislation, an organization should take the time to note and be aware of other legal complications connected to regulating student-athlete usage of social networking websites.

Social media guidelines are similar to social media bans due to the lack of connection to privacy legislation. Typically, social media guidelines are used to warn student-athletes of the dangers associated with using social networking sites. If these guidelines are only being offered as an educational resource to make studentathletes aware of who is watching their activity on social media, then it can be viewed as only a cautionary and educational notification. However, if there is any punishment or consequences from the university attached to the social media policy, then the likelihood increases that athletic staff is monitoring these sites. That monitoring is exactly what access legislation attempts to limit and should be considered when developing the guidelines.

For those policies that explicitly state that monitoring will be conducted, organizations must make sure that their monitoring is conducted in a legal manner. This caution should be used whether or not the school or university is located within a state that has existing social media legislation directed at educational institutions. The Minnewaska school district in Minnesota found themselves in a situation where a legal challenge to their social media policy for students was initially successful (R.S. et al v. Minnewaska, 2012). 
They did settle the case out of court to avoid further responsibility, but the fact that the case did survive an initial motion for summary judgment highlights the growing trend towards privacy even in states without specific social media privacy legislation.

A successful social media monitoring policy should focus its monitoring efforts on publicly available information. Of the ten social media access laws that applies to educational institutions, each one prohibits requests or requirements for social media usernames or passwords. Asking for this information is precisely why social media legislation was enacted. It has been repeatedly considered a violation of privacy when this information must be provided as a condition of employment or participation (Poerio \& Bain, 2012). Along the same lines, requiring or requesting student-athletes to follow or friend one of the team's coaches or administrators can create legal problems for an organization. This too is will likely be considered a violation of privacy because the rule applies to all student-athletes, regardless of whether their accounts are public or private.

When Brandeis and Warren wrote on the basis of privacy law in this country, the main purpose was to protect information that others wished to be kept private. All social media users have the option of limiting access to their accounts through privacy controls. If a university was to require or request access to these locked accounts, it would be a direct violation of their privacy because the methods used to limit access would become worthless. It does not matter that many of these student-athletes are willing to give up their privacy for the sake of participation. All it takes is one studentathlete complaint about privacy to derail an entire team or department's social media monitoring goals. Currently, there are no lawsuits filed challenging the right of privacy in relation to social media monitoring and associated punishments in the post-secondary educational setting, but that doesn't mean a university can completely ignore the possibility especially as social media related controversies grow. By carefully tailoring social media monitoring policies within the parameters of existing legal trends, an organization will be able to achieve the results of monitoring with 
minimal threat of liability from both NCAA regulations and changing state law.

Based on current law, universities can avoid violation of privacy claims by focusing on publicly available information on social media sites. This method does require conducting searches for student-athlete social media accounts that could be an extensive and tedious process, but allows you to achieve similar results. According to the 2012 Fieldhouse Media survey on social media use by studentathletes, $64.1 \%$ of student-athletes have a public Twitter account. Student-athletes tend to use the privacy settings more on Facebook and Instagram, with $96 \%$ using the privacy settings on Facebook and $60 \%$ private accounts on Instagram (DeShazo, 2013). The use of privacy settings may make monitoring more difficult, but the majority of social media related violations have been connected to Twitter. Additionally, social media accounts are often linked. If a student-athlete posts a photo to Instagram, a link could be created through their Facebook or Twitter account that allows you to see the photo.

In some instances, universities may be able to streamline this process with the use of a third-party monitoring company. These sites take on the work of monitoring the activity of student-athletes and may be able to gain access to private accounts if those students willingly accept invites from those working for third-party monitoring organizations. You must use these sites with caution. For example, in Utah, use of these third-party monitoring organizations is considered an illegal way to monitor student-athletes. Beyond that, each team and university also needs to make sure that these organizations are protecting the privacy of student-athletes in the same manner you would use with in-house monitoring. Social media monitoring does not need to be a particularly invasive process because the majority of information is publicly available.

\section{Conclusion}

As social media usage grows in our society, so too have concerns regarding privacy increased. The right to privacy initially 
began as a method to protect information that others wished to be kept private with publicly posted information not considered for privacy regulation. Social media provides complication because the whole purpose of these sites is to publish information to be seen by others. Law is quickly catching up to technology and providing a challenge for those who would like to be able to monitor the social media activity of their representatives. The growing legal trend in relation to social media is to protect the privacy of social media users from other organizations. In general, any request or requirement of social media access is being met with legislation declaring this to be a violation of privacy.

The original concerns associated with social media for athletic organizations are still present. Student-athletes are often prone to make the mistakes of youth, which are further amplified and publicized through social media. A cautious team or athletic department must be concerned about social media activity, but that concern must proceed with caution. Social media monitoring is legal when used properly. Even if the state where the university is located currently does not have social media legislation, whether that means no existing legislation entirely or no legislation applicable to educational institutions, an organization is best served by limiting their monitoring capabilities as a means of protecting privacy interests. Focusing on publicly available accounts and information avoids the privacy concerns because anything made public cannot assume the same right of privacy available to locked accounts. Additionally, this monitoring must be done through searches instead of requests or requirements from student-athletes to share their information with the team or athletic department. This method is more tedious but can provide the same information in a legally responsible manner.

Social media monitoring does not need to be a complex and stressful process for teams and athletic departments. When monitoring is combined with educating student-athletes about the dangers of social media, you can minimize the risk of potentially damaging information being published online. Student-athletes need 
to be aware of the fact that anyone can see what they post online, especially on a publicly available account. Monitoring by athletic teams or by staff connected to the athletic department will help to make them more cautious and aware of their actions. Further, when these assigned social media monitors stick to publicly available information, you can prevent or manage the information more likely to be damaging while maintaining a safe respect for an individual's right to privacy. 


\section{References}

Benitez, G. (2014, March 28). ABC News. Retrieved from School District Pays $\$ 70 \mathrm{~K}$ to Settle Lawsuit Over Girl's Facebook Posts: http://abcnews.go.com/US/school-district-pays-70ksettle-lawsuit-online-posts/story?id=23094873

Brenner, J., \& Smith, A. (2013, August 5). 72\% of Online Adults are Social Networking Site Users. Retrieved from Pew Research Center: http://pewinternet.org/Reports/2013/socialnetworking-sites.aspx

Browning, B., \& Sanderson, J. (2012). The Positives and Negatives of Twitter: Exploring How Student-Athletes Use Twitter and Respond to Critical Tweets. International Journal of Sport Communication, 503-521.

Sherman, E. (2014, April 14). Many Twitter users don't tweet, finds report. Retrieved from CBS Money Watch: http://www.cbsnews.com/news/many-twitter-users-donttweet-finds-report/

Staples, A. (2012, January 24). For top football recruits, behavior on social media has consequences. Retrieved from Sports Illustrated: http://sportsillustrated.cnn.com/2012/writers/andy_staples/01 /24/recruits.social.media/

Browning, B, \& Sanderson, J. (2013). Training Versus Monitoring: A Qualitative Examination of Athletic Department Practices Regarding Student-Athletes and Twitter. Qualitative Research Reports in Communication, 105-111.

College Sports Information Directors of America. (2012, March 21). CoSIDA Survey Results: The state of crisis communications in college athletics. Retrieved from http://www.cosida.com/news.aspx?id=3603 
College Sports Information Directors of America. (2013, March 13). 2013 CoSIDA Membership Survey: Social Media Training for Student-Athletes and Coaches. Retrieved from http://cosida.com/media/documents/2013/3/2013_CoSIDA_S urvey_Results_Final1.pdf

DeShazo, K. (2013, March 11). Social Media Use of Student Athletes [survey results]. Retrieved from Fieldhouse Media: http://www.fieldhousemedia.net/social-media-use-of-studentathletes/

Duggan, M., \& Brenner, J. (2012). The Demographics of Social Media Users . Pew Research Center.

Giglio, J. (2010, July 20). Austin's Twitter account sheds light on UNC player. Retrieved from News Observer: $\mathrm{http} / / /$ blogs.newsobserver.com/accnow/austins-twitteraccount-provides-clues-in-ncaa-probe-at-unc

Gormley, K. (1992). One Hundred Years of Privacy. Wisconsin Law Review.

Hopkins, J. P., Hopkins, K., \& Whelton, B. (2013). Being Social: Why the NCAA Has Forced Universities to Monitor StudentAthletes' Social Media. University of Pittsburgh Journal of Technology Law \& Policy, 13 PGH. J. Tech. L. \& Pol'y 1.

House Bill 309 (2012). Delaware

House Bill 964 (2012). Maryland

House Bill 1902 (2013). Arkansas

House Bill 2654 (2013). Oregon

Infractions, N. C. (2012, March 12). University of North Carolina, Chapel Hill Public Infractions Report. Retrieved from Chronicle of Higher Education: http://chronicle.com/blogs/ticker/files/2012/03/UNC.pdf

Internet Privacy Amendments. House Bill 100 (2013). Utah Internet Privacy Protection Act. 2012 Mich. Acts 478. 28

Dec. 2012 
Kwoh, L. (2012, October 29). Beware: Potential Employers are Watching You. Retrieved from Wall Street Journal: http://online.wsj.com/article/SB10000872396390443759504 577631410093879278.html

Maryland Athletics: Social Media Guidelines for Student-Athletes. (2011, October 13). Retrieved from http://www.washingtonpost.com/r/20102019/WashingtonPost/2011/10/13/CapitalBusiness/Graphics/ Student $\% 20$ Athlete\%20Social\%20Media\%20Guidelines.pdf

Michigan Athletics: Social Media Guidelines. (n.d.). Retrieved from http://www.annarbor.com/University $\% 20$ of $\% 20$ Michigan $\% 2$ 0social\%20media\%20guidelines\%20for\%20athletes.pdf

National Conference of State Legislatures. (2013, January 17). 2012 Legislation relating to employer access to social media usernames and passwords. Retrieved from http://www.ncsl.org/issues-research/telecom/employeraccess-to-social-media-passwords.aspx

National Conference of State Legislatures. (2013, September 12). Employer Access to Social Media Usernames and Passwords 2013. Retrieved from http://www.ncsl.org/issuesresearch/telecom/employer-access-to-social-mediapasswords-2013.aspx

National Conference of State Legislatures. (2014, April 10). Employer Access to Social Media Usernames and Passwords 2014. Retrieved from http://www.ncsl.org/research/telecommunications-andinformation-technology/employer-access-to-social-mediapasswords-2013.aspx\#2014

Oregon State University. (n.d.). Social Media Tips. Retrieved from http://oregonstate.edu/main/social-media-guide

Park University Athletics Guidelines for the Use of Social Media. (n.d.). Retrieved from http://www.parkathletics.com/piratepost/park_university_athl etics_social_media_guidelines.pdf 
Patterson, C. (2013, May 10). Columbia officials release statement on hate crime, Twitter use. Retrieved from CBS Sports: http://www.cbssports.com/collegefootball/blog/eye-oncollege-football/22225511/columbia-officials-releasestatement-on-hate-crime-twitter-use

Penrose, M. (2013). Outspoken: Social Media and the Modern College Athlete. The John Marshall Law School Review of Intellectual Property Law. 12 J. Marshall Rev. Intell. Prop. L 509.

Poerio, J. M., \& Bain, L. E. (2012). Social Media in the Workplace: Employer Protections versus Employee Privacy. Retrieved from American Bar Association:

http://www.americanbar.org/publications/international_law news/2012/fall/social_media_workplace_employer_protectio ns_versus_employee_privacy.html

Poore, M. (2013). A Call for Uncle Sam to Get Big Brother Out of Our Knickers: Protecting Privacy and Freedom of Speech Interests in Social Media Accounts. Northern Kentucky Law Review, 40 N. Ky. L. Rev. 507.

Prince Albert v. Strange, 41 Eng. Rep. 1171(1849). Public Act 098-0129 (2013). Illinois Publishing to Twitter from Facebook pages. (n.d.). Retrieved from Facebook:

http://blog.facebook.com/blog.php?post=123006872130

R.S. v. et al v. Minnewaska Area School District No. 2149 et al, Civ. No. 12-588 (MJD/LIB) (2012).

Sanderson, J. (2011) To Tweet or not to tweet....: Exploring Division I athletic departments' social-media policies. International Journal of Sport Communication, 4, 492-513. Schwab, F. (2013, May 9). Report: Columbia football players' offensive tweets revealed after player charged with hate crime. Retrieved from Yahoo Sports: http://sports.yahoo.com/blogs/ncaaf-dr-saturday/columbiafootball-players-racist-homophobic-tweets-revealed-player170746947.html 
Senate Bill 223 (2013). Wisconsin

Senate Bill 422 (2013). New Mexico

Senate Bill 1349 (2012). California

Sherman, E. (2014, April 14). Many Twitter users don't tweet, finds report. Retrieved from CBS Money Watch:

http://www.cbsnews.com/news/many-twitter-users-donttweet-finds-report/

Browning, B., \& Sanderson, J. (2012). The Positives and Negatives of Twitter: Exploring How Student-Athletes Use Twitter and Respond to Critical Tweets. International Journal of Sport Communication, 503-521.

Sherman, E. (2014, April 14). Many Twitter users don't tweet, finds report. Retrieved from CBS Money Watch: http://www.cbsnews.com/news/many-twitter-users-donttweet-finds-report/

Staples, A. (2012, January 24). For top football recruits, behavior on social media has consequences. Retrieved from Sports Illustrated:

http://sportsillustrated.cnn.com/2012/writers/andy_staples/01 /24/recruits.social.media/

Using Twitter with Facebook. (n.d.). Retrieved from Twitter:

https://support.twitter.com/articles/31113-using-twitter-with facebook

Walsh, M. (2010, October 18). Twitter banned for UNC football. Retrieved from Daily Tar Heel: http://www.dailytarheel.com/article/2010/10/twitter_banned_ for unc football

Warren, S., \& Brandeis, L. (1891). The Right of Privacy. Harvard Law Review. 


\section{About The Journal of SPORT}

The Journal of SPORT brings together in one journal the wide variety of research disciplines in sport and will be published biannually in Summer (July/August) and Winter (January/February). The Journal of SPORT is published by the Center for Sport and Recreation Development at Kent State University. A faculty Advisory Board composed of nationally, as well as internationally recognized faculty participates in the peer mentorship review process. This unique, but distinctive, mentorship process provides opportunities for graduate students, at an array of institutions, to thoroughly analyze and review research in conjunction with a faculty mentor. The number of articles accepted will be limited through a selective review process. After the faculty mentored peer review is completed a final determination is made to accept or reject the article. The Journal of SPORT encourages faculty and/or students to submit their research for review.

\section{Submission Guidelines}

See www.thejournalofsport.com for Submission Guidelines.

\section{Editor}

Mark Lyberger

Kent State University

\section{Production Coordinator}

\section{Aaron Mulrooney}

Kent State University 
Student Review Board

Patrick Gentile

Kent State University

Andrew Gerow

Kent State University

Sean Hanus

Kent State University

Karlie Hepburn

Kent State University

Mike Jones

Kent State University

Ashley Just

Kent State University

Zach Keller

Kent State University

Sean Offerdahl

Kent State University

Editorial Review Board (Volume 3 Issue 2)

Charles Campisi

Baldwin Wallace University

Walter Davis

Kent State University

Judy Devine

Kent State University 


\title{
Michael Duve \\ University of Akron
}

\section{G. Leticia Gonzalez}

Kent State Univesity

Marta Guivernau

Kent State University

Richard Hunter

Seton Hall University

Sun J. Kang

The Ohio State University

\author{
Alan Kornspan \\ University of Akron \\ Jennifer Kulics \\ Kent State University \\ Seungbum Lee \\ University of Akron
}

Laurence McCarthy

Seton Hall University

Mauro Palmero

East Tennessee State University

Megan Parietti

The Ohio State University

Randale Richmond

Kent State University 


\section{Kimberly Schimmel}

Kent State University

Per Svensson

University of Louisville

\section{Patrick Sweeney}

Kent State University

\section{Theresa Walton}

Kent State University 